\title{
Recent Advances in Protective Coatings for Cultural Heritage-An Overview
}

\author{
Alessia Artesani ${ }^{1,+}\left(\mathbb{C}\right.$, Francesca Di Turo ${ }^{1,+} \oplus$, Margherita Zucchelli ${ }^{1,2}$ and Arianna Traviglia ${ }^{1, *}$ \\ 1 Center for Cultural Heritage Technology (CCHT), Istituto Italiano di Tecnologia (IIT), 13175 Marghera, Italy; \\ alessia.artesani@iit.it (A.A.); francesca.dituro@iit.it (F.D.T.); margherita.zucchelli@iit.it (M.Z.) \\ 2 Dipartimento di scienze molecolari e nanosistemi (DSMN), Università Ca' Foscari, via Torino 155,30172 \\ Venezia Mestre, Italy \\ * Correspondence: arianna.traviglia@iit.it \\ + These authors contributed equally to this work.
}

Received: 30 January 2020; Accepted: 27 February 2020; Published: 29 February 2020

check for

\begin{abstract}
In the last decades, the interest in the development of protective coatings for movable and immovable Cultural Heritage $(\mathrm{CH})$ assets has decidedly increased. This has been mainly prompted by the raising consciousness on preservation requirements for cultural artefacts and monuments, which has consequently determined the development of new protective products. From acrylic resins used at the end of the last century to the up-to-date biomaterials and nanoparticles employed nowadays, the research has made a giant step forward. This article reviews the progresses, the technical challenges, and the most recent advances in protective coatings for archaeological metal, glass, and stone artefacts. It aims at offering a comprehensive and critical overview of the progressions in conservation science and displaying how research has optimized polymers in order to solve deterioration problems. Attention is given to recently developed materials, hybrid coatings, and corrosion inhibitors. This work seeks to provide a reference point for future research and to offer a wide-ranging introduction on the newly available material technologies to restorers and conservators.
\end{abstract}

Keywords: protective coatings; cultural heritage; metals; glass; stones

\section{Introduction}

Movable and immovable Cultural Heritage $(\mathrm{CH})$ assets are often exposed to multiple risks that can undermine their integrity, causing damage and loss of value. Their deterioration is strongly correlated to the specific location and context in which they exist. Although $\mathrm{CH}$ assets held in indoor environments are normally maintained in near-to-ideal conditions through the monitoring of environmental parameters (i.e., relative humidity, temperature, light) that might affect them, those located or held outdoors have to face exposure to weathering and the presence of reactive compounds in the atmosphere that can interact with the materials they are made of. This is the case, for example, of still buried archaeological items (irrespectively if covered by soil or water), monuments, or decorative elements that endure severe degradation.

In the last decades, a variety of protective coatings have been developed for preserving the integrity of the $\mathrm{CH}$ items and slowing down the degradation process through the reduction of the deterioration rate. Coatings engineered for cultural items should normally conform to the widely accepted standards of restoration [1], which provide the characteristics of an ideal protective coating: transparency, reversibility, compatibility with the surface, long-term lifetime, easy synthesis, low-cost maintenance, and non-toxicity.

The challenge is the development of new products that enclose all these features. Some of these characteristics regard safety and security rules for both objects and operators. The synthesis and the 
application of the coating should be as much as possible (or totally) green and risk-free for conservators and restorers. The same safety rules should be respected for the eventual removal of the protective film that should be carried out using non-toxic solvents. From purely aesthetic side, the original appearance of an archaeological or artistic object should be maintained unchanged. In other contexts, this would be a secondary aspect, but when considering the $\mathrm{CH}$ materials, it is fundamental and complicates the choice of the appropriate protective coating. Even if the coating is transparent when applied, it can change colour over time due to the interaction with the environment and photo-oxidation mechanisms, which most of the time cause the yellowing of the film. This tendency can be accepted as long as the coating can be removed from the surface without compromising the surface itself. This last need suggests that the coating must be reversible. Finally, the long-term life of protective coating is generally preferred both for the preservation point of view and for maintenance costs.

The awareness about the characteristics that coatings should display have changed over the years and protective coatings developed 30 years ago may not have all the features required today. Concurrently, the technology available for developing new coating products has evolved, and coating science has progressed as well. In this review, we consider the advances made in the last 20 years in protective coatings for archaeological materials for proposing to the reader a critical review of the progress made in conservation science. The aim of this work is to establish the state-of-the-art applications in this field in order to stimulate the research to go beyond the present limits by testing and synthesizing new coatings with adequate features for $\mathrm{CH}$ materials.

In the following sections of this work, degradation phenomena of the considered materials are illustrated in broad terms, as they are indispensable for the thorough understanding of the preservation requirements. Historical surfaces usually have complex morphology because of porosity, various compositions, and the presence of microorganisms, all aspects that must be considered before the application of protective films. The investigation on the alteration products and the evaluation of the degradation impact on historical surfaces are not always straightforward or univocal. For this reason, a multi-analytical approach is often required. The techniques frequently used to investigate the archaeological surface are briefly listed below in order to anticipate to the reader the required preliminary analysis for a comprehensive study of the material. The morphology of the external structures is often studied with Scanning Electron Microscopy (SEM), combined with Energy Dispersive Spectroscopy (EDS), for obtaining a semi-quantitative analysis of the compounds formed on the surface. X-Ray Fluorescence (XRF), Fourier Transform Infrared (FTIR) spectroscopy, Raman spectroscopy, and X-Ray Diffraction (XRD) are instead extensively used for the chemical and mineralogical characterization, as well as for testing the correct ageing processes on modern samples by the monitoring the formation of alteration compounds. When possible, XRD can serve also to study samples of archaeological patina, whereas X-Ray Photoelectron Spectroscopy (XPS) gives information on the oxidation state of metals. The characterization and evaluation of the corrosion inhibition effects of the coating are studied mainly by electrochemical techniques, where the electrochemical impedance spectroscopy (EIS) is one of the most used. It gives the information about the resistance of the coating and then its protectiveness properties. Finally, Gas Chromatography (GC) and Differential Thermal Analysis (DTA) are applied mainly for determining the degradation products, evaluating the effectiveness of a coating under various thermal conditions.

In the next paragraphs, the most frequently used coatings in the past are presented, evaluating the advantages and limits of their application and how science has overcome problems related to compatibility, transparency, and toxicity. Although it is not yet possible to find a protective coating that owns all the ideal properties required for the application on $\mathrm{CH}$ materials, a discussion on the potentiality of the last advances in this sector is conducted. Because this work would represent a guide for future coating application for archaeological and artistic materials, it focuses on the state of the art of protective coatings for specific materials, namely, metallic surfaces, historical glass, and stones, which more frequently are subject to aggressive environments. It aims to be as comprehensive as possible in order to be a starting point for new syntheses and applications. 
The review is sectioned accordingly to material type. In fact, despite good coating solutions have been frequently adapted for different surfaces, the pros and cons for each type of materials are better highlighted in this was. We here anticipate the topic that one of the most shared conservative approaches to date has been the use of polyester resins and acrylics or vinyl polymers as consolidating agents [2]. These kinds of applications have been particularly diffused starting from the 1970s. Paraloid B72, polyvinyl acetate emulsion (PVAc), and PrimalAC-33 are still employed nowadays for stabilizing the surface of frescos, stone materials, and glass windows [3]. Despite general approval, these acrylic resins are demonstrated as not being the optimal choice because of their tendency to undergo photo-oxidation reactions, which is principally induced by the sunlight action and enhanced by temperature and atmospheric pollution [4]. The photo-oxidation processes are critical for the long-term effectiveness of the coating because they induce the yellowing of the coating and reduce the resistance to degradation. It is for these reasons that the authors of this review consider surpassing the use of acrylic resins on $\mathrm{CH}$ materials, and prefer to draw the attention of the reader to future trends in protective coating research and provide evidence for the main positive qualities of the newly proposed protective actions.

\section{Metallic Objects}

The use of metals and their alloys have been fundamental in technological evolution over time. The ability to extract and process different kinds of metals in antiquity determined the supremacy and the political success of one civilization over the others. Metals have been largely used not only for the creation of utensils and movable items but also as constituents of buildings or for their decoration. Metallic $\mathrm{CH}$ objects can be either significantly ancient-archaeological artefacts, buried for centuries and displaying severe degradation issues-or relatively recent—such as, for example, statues and sculptures exposed to outdoor environmental conditions. Both kinds are extremely fragile and they require appropriate protection, which can be achieved by the application of a coating film.

The main problem for the conservation of metallic objects is associated with the progression of corrosion. Corrosion is an irreversible electrochemical reaction between the metal and compounds present in the environment, which lead to the alteration of the original metal or alloy. The most important point concerning the metal protection is the impossibility to stop the corrosion, whose rate can only be slow down. The chemical attack is often accompanied by erosion and wear of the metallic surface, which involves the physical degradation of the object [5]. In general terms, corrosion is promoted by the presence of water and oxygen, whereas their combination with acids accelerates the deterioration mechanisms, which are mainly responsible for the lifespan reduction of materials [6-8].

The corrosion processes are different depending on the metal or alloy, and this consequently affects the protective actions needed for the materials. The understanding of the undergoing corrosion mechanisms is essential for developing an adequate protective coating and improving its preservation. A brief reminder of the main mechanisms of the patina formation are explained in order to go into details on the protective coating designed for specific corrosion issue. Over the ancient history, copper-based alloys were the most diffused. Amongst these, bronze (Cu-Sn) is one of the most important. It was used for the fabrication of coins, weapons, and everyday objects. Consequently, this material gains attention of researchers. Robbiola et al. [9] studied in depth the mechanisms of bronze corrosion, and this work can be considered a fundamental text in this context. It makes light on the noble and vile patina formation - the former acts as a protective coating, whereas the latter leads to the degradation of the metal object. This is because the two patinas have different composition and layer structure. Noble patina is mainly composed of copper and tin oxides $\left(\mathrm{CuO}, \mathrm{Cu}_{2} \mathrm{O}, \mathrm{SnO}\right)$ and the decuprification phenomenon causes the migration of cuprite in the external layers, helping the passivation of the surfaces. Conversely, the vile patina is characterised by several layers of alteration compounds where those with chlorine content are the most dangerous. The interaction of copper with the chlorine compounds causes the formation of nantokite $(\mathrm{CuCl})$. This is the first step of the well-known corrosion process denominated as "corrosion disease". $\mathrm{CuCl}$ determine the formation of the hydroxychloride 
compounds, i.e., the atacamite polymorphs, $\mathrm{Cu}_{2}(\mathrm{OH})_{3} \mathrm{Cl}$. This patina is very dangerous for metal surface because it leads to the pulverization, and thus the complete destruction of the bronze object [9]. The general reaction that involve the formation of $\mathrm{CuCl}$ and its compounds can be written as:

$$
\begin{gathered}
\mathrm{Cu}_{(\mathrm{s})}+\mathrm{Cl}_{(\mathrm{s})}^{-} \rightarrow \mathrm{CuCl}_{(\mathrm{s})}+\mathrm{e}^{-} \\
4 \mathrm{CuCl}_{(\mathrm{s})}+\mathrm{O}_{2(\mathrm{~g})}+4 \mathrm{H}_{2} \mathrm{O} \rightarrow 2 \mathrm{Cu}_{2}(\mathrm{OH})_{3} \mathrm{Cl}_{(\mathrm{s})}+2 \mathrm{HCl}_{(\mathrm{aq})}
\end{gathered}
$$

Another common copper-based alloy in antiquity is $\mathrm{Ag}-\mathrm{Cu}$, often used for coins and jewellery. In this case, the less noble metal (copper) suffers by corrosion, whereas the formation of a superficial patina of cuprite $\left(\mathrm{Cu}_{2} \mathrm{O}\right)$ help this alloy to be preserved, acting as passivating patina [10]. Another possible corrosive reaction, which involves silver as principal actor, includes the formation of chlorargyrite $(\mathrm{AgCl})$ and/or silver tarnish $\left(\mathrm{Ag}_{2} \mathrm{~S}\right)$. On the contrary, $\mathrm{Cu}$ is mainly implicated in the formation of minerals of malachite $\left(\mathrm{Cu}\left(\mathrm{CO}_{3}\right) \mathrm{Cu}(\mathrm{OH})_{2}\right)$ or atacamite group $\left.\left(\mathrm{Cu}_{2}(\mathrm{OH})_{3}\right) \mathrm{Cl}\right)$ [11].

Brass, or orichalcum in ancient times, is a $\mathrm{Cu}-\mathrm{Zn}$ alloy. Romans produced brass coins improving the cementation process-the zinc vapours spread into the copper melt, obtaining an alloy with approximately $30 \%$ zinc and $70 \%$ copper [12]. The most important problem regarding the corrosion of brass alloys is the dezincification phenomenon, which is still being investigated. In fact, dezincification can be due to the selective dissolution of $\mathrm{Zn}$ or the simultaneous dissolution of $\mathrm{Cu}$ and $\mathrm{Zn}$ followed by the redeposition of $\mathrm{Cu}[13,14]$. In the first hypothesis, copper atoms do not participate in the process, whereas in the simultaneous dissolution both metals are involved in causing a defective metallic $\mathrm{Cu}$ layer. The degree of this phenomenon depends on the percentage of $\mathrm{Zn}$ in the alloy and the possible presence of minor elements (i.e., As, $\mathrm{Fe}, \mathrm{Sb}, \mathrm{P}$ ). Generally, humidity is considered dangerous for brass alloy [15]. However, researchers always find difficulties in explaining the mechanisms of brass corrosion because of the complex nature of the metallic layer formed after the dezincification $[15,16]$. Furthermore, studies concerning the corrosion of brass consider commercial and standard samples to assess the corrosion mechanisms, whereas the corrosion of archaeological brass can be influenced by other factors (such as manufacturing processes, burial environment, and provenance) that cannot be reproduced with artificial ageing.

Bronzes are not the only unique material to be threatened by chlorine ions. The latter are dangerous also for iron artefacts, a metal used extensively in the past to produce weapons. Rust is the most common way to indicate the unstable $\mathrm{Fe}(\mathrm{II})-\mathrm{Fe}(\mathrm{II})$ hydroxy salts that can oxidize when sufficient oxygen is present in the environment [17]. The reaction with chlorine forms very unstable compounds prone to pulverization. One of the most dangerous corrosion products for iron is the iron-oxide mineral containing chloride, namely, the akaganeite. Its formation occurs when the iron oxides $\left(\mathrm{Fe}_{3} \mathrm{O}_{4}\right.$, magnetite) react with the chlorine of the environment [17-20]. A more complex situation in terms of iron reactions and corrosion can be found for all those submerged artefacts after a shipwreck [21], for which the conservation is complicated by the double exposure to the atmosphere and water.

In Figure 1, the corrosion processes of the considered metals are schematised, showing the different formation of the protective or vile patina for bronzes (Figure 1a), the interaction of $\mathrm{Cu}$ with environment compound in the Ag-Cu alloy (Figure 1b) and the possible corrosion phenomenon of brass (Figure 1c). Table 1 summarizes the most common mineralogical compounds that can characterize the surface patina of archaeological metals.

As briefly illustrated in this section, the number of materials and corrosion issues are broad, although some similarities can be found. In order to evidence the best coating solutions for different metals, in the next paragraphs the attention is focused first on the coating developed to preserve copper and bronze alloys. This topic engages a large part of the present research because of their diffusion and interest, while a second section is dedicated to other archaeological metals, such as silver and iron alloys. 
a)

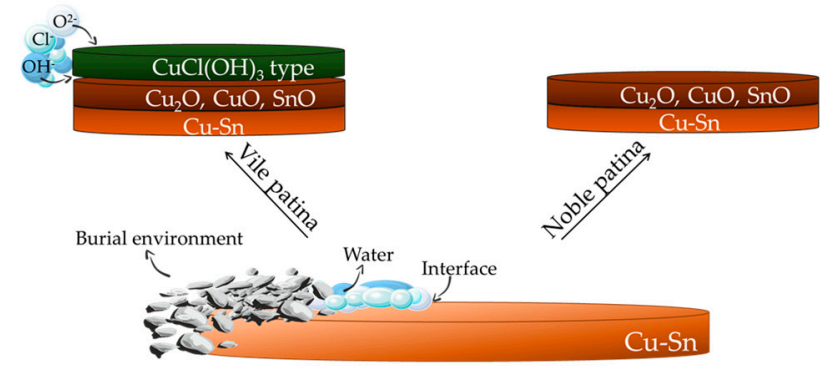

b)

c)
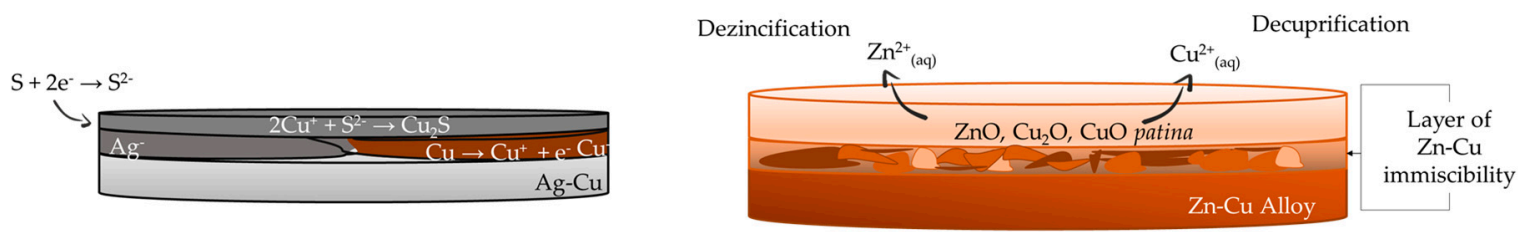

Figure 1. Schematized corrosion process of (a) bronze, (b) silver, and (c) brass with the formation of alteration compounds on the metal surface.

Table 1. List of the most common corrosion products on different metal substrates.

\begin{tabular}{|c|c|c|}
\hline Element & Chemical Formula & Mineralogical Name \\
\hline \multirow{4}{*}{$\mathrm{Cu}$} & $\mathrm{Cu}_{2} \mathrm{O}$ & Cuprite \\
\hline & $\mathrm{CuO}$ & Tenorite \\
\hline & $\mathrm{CuCO}_{3} \mathrm{Cu}(\mathrm{OH})_{2}$ & Malachite \\
\hline & $2 \mathrm{CuCO}_{3} \mathrm{Cu}(\mathrm{OH})_{2}$ & Azurite \\
\hline \multirow{3}{*}{$\mathrm{Cu} / \mathrm{Cl}$} & $\mathrm{CuCl}$ & Nantokite \\
\hline & $\mathrm{Cu}_{2}(\mathrm{OH})_{3} \mathrm{Cl}$ & Atacamite and polymorphs \\
\hline & $\mathrm{Cu}_{2} \mathrm{~S}$ & Chalcocite \\
\hline \multirow[t]{2}{*}{$\mathrm{Cu} / \mathrm{S}$} & $\mathrm{CuS}$ & Covellite \\
\hline & $\mathrm{CuSO}_{4} 2 \mathrm{Cu}(\mathrm{OH})_{2}$ & Brochantite \\
\hline \multirow[t]{2}{*}{ Sn } & $\mathrm{SnO}$ & Tin(II) oxide, stannous oxide \\
\hline & $\mathrm{SnO}_{2}$ & Cassiterite \\
\hline $\mathrm{Pb}$ & $\mathrm{PbO}$ & Litharge/massicot \\
\hline \multirow[t]{2}{*}{$\mathrm{Ag}$} & $\mathrm{Ag}_{2} \mathrm{~S}$ & Acanthite \\
\hline & $\mathrm{AgCl}$ & Chlorargyrite \\
\hline \multirow[t]{2}{*}{$\mathrm{Fe}$} & $\mathrm{Fe}_{3} \mathrm{O}_{4}$ & Magnetite \\
\hline & $\begin{array}{c}\left(\mathrm{Fe}^{3+}, \mathrm{Ni}^{2+}\right)_{8}(\mathrm{OH}, \mathrm{O})_{16} \mathrm{Cl}_{1.25} \\
\cdot \mathrm{nH}_{2} \mathrm{O}\end{array}$ & Akaganeite \\
\hline $\mathrm{Zn}$ & $\mathrm{ZnO}$ & Zincite \\
\hline
\end{tabular}

\subsection{Copper and Bronzes}

The interaction between water and oxygen of the environment and the metal surface induces the formation of a surface patina over time, which can make the protection of copper and bronze particularly complex, as described previously. Conservators and restorers usually prefer to keep the natural patina on archaeological metals, as it can have a self-protecting effect for the surface and its removal could damage the already fragile object. Moreover, the greenish patina gives a good appearance to the object, evidencing its authenticity, and thus bronze artefacts are generally exposed in museums together with their patina layers for this reason. It should be mentioned that, in addition to the original patina, other corrosive mechanisms could be activated when the object is removed from its burial environment because of the different hygrometric conditions. Until it is buried, the bronze object is in equilibrium with the surrounding sediment, and in some sense, it is preserved. Once extracted, the environmental changes accelerate the corrosion. In this view, preventive action should be implemented in order to reduce the impact of external factors and reinforce the self-protecting effects sometimes 
given by the natural patina. Despite the fact that testing protective coating directly on archaeological metals would be the most truthful way for understanding the efficacy of the applied products, research often makes use of aged specimens and only in rare cases uses archaeological artefacts. This because of the preciousness of the objects, which limits the direct application, but at the same time it reduces the confidence of restorers and conservators on the use of new products or protective treatments.

In the last 20 years, the most experimented coating to protect copper and its alloys have been triazoles and silanes, whereas more recently more innovative solutions, such as nano-composites and bio-polymers, have been explored. Before the discussion on these mostly diffused and studied protective coatings, we mention here for the sake of completeness the two kinds of surface treatments that have been exploited on metals but for different reasons cannot be retained good for protecting $\mathrm{CH}$ metals. The first one is represented by organic coatings and acrylic resins (the Paraloid family, for example), which have been for a long time the preferential choice for many $\mathrm{CH}$ materials, as anticipated in the Introduction section. Despite their good mechanical properties and good adhesion, it has been widely demonstrated that this class of resins is not adequate due to their incompatibility with both metallic substrate and original patina. Resins show cracking problems and colour changes in a short period of time, especially if the metallic object is exposed to moderate temperature and sunlight [22].

The second application is plasma polymer coating (PPC), tested for the first time on both modern and archaeological samples by Favre-Quattropani et al. [23]. This study is a unique example of PPC for ancient metal conservation, as these kinds of coatings were used mainly for technological applications, such as the protection of metallic conductors in microelectronics circuits [24]. Favre-Quattropani and collaborators suggested the use of PPC for creating a barrier against oxygen and water. The results of these tests on historical metals showed that the deposit effectiveness of the coating was good for all the copper/bronze specimens. The resistance against $90 \%$ of relative humidity (RH) for 11 days was very high, because as they carried out tests in extreme conditions, the coatings did not show delamination phenomena, remaining attached to the metal surface, although a significant oxidation of the film due to the environmental exposure was detected through XPS analyses. It should be mentioned, however, that PPC presents some problems in terms of application on $\mathrm{CH}$ metals. First, the coating does not dissolve when the object is immersed in a solvent (acetone or ethanol). This can be a problem for the reversibility and for its removal using a "green" approach. Secondly, as highlighted by the authors, there was a problem of colouration of the coating, maybe due to some interaction of $\mathrm{C}=\mathrm{C}$ bonds after the electrochemical measurements. The thinnest coating (around $5 \mathrm{~nm}$ ) showed a yellow colour, whereas the thicker coating had an opaque and dark colour. Moreover, the low thickness (evaluated around $10 \mathrm{~nm}$ ) gave chemical stability but low mechanical strength, and thus it was not possible to use them on fragile objects, limiting the possibilities of application. Plasma polymer coatings are not yet studied extensively in the field of archaeological metals, although they present interesting properties. On the other side, plasma coatings are not easy to produce, as they require a specific equipment and restricted conditions for both synthesis and application. One of the main objectives in the research concerning coatings for cultural heritage is the possibility of synthesizing films easily, allowing the restorers to handle the chemical products developed ad hoc for the substrate.

\subsubsection{Triazole Derivatives}

The first protective coating tested on archaeological metals was triazole and its derivatives. Triazoles have a long history in metallic protection because they were used as an inhibitor of copper corrosion in the industrial field [25-27]. The compounds are heterocyclic molecules with general chemical formula $\mathrm{C}_{2} \mathrm{H}_{3} \mathrm{~N}_{3}$, having a five-membered ring of two carbon atoms and three nitrogen atoms (Figure 2). [28] The major advantages of triazole and its derivatives are their transparency and reversibility, as they can be removed by immersing the sample in an alcohol medium. Amongst different triazole-based compounds, the research highlighted the benzotriazole (BTA, $\mathrm{C}_{6} \mathrm{H}_{5} \mathrm{~N}_{3}$ ) as it is the most efficient inhibitor at rather low concentration. BTA is diffusively applied in corrosion science, as reviewed by Finsgar and Milosev [26], and it is the most successful commercial inhibitor used also 
in conservation practice since the last decade. Amongst its advantages appreciated for archaeological metals, BTA counts its long-lasting life in a chloride-rich environment and its effectiveness in inhibiting hydrolysis of $\mathrm{CuCl}$ to $\mathrm{Cu}_{2}(\mathrm{OH})_{3} \mathrm{Cl}$, which is evaluated at 99\% [27]. Additionally, BTA confirms its elevated anti-corrosion performances on copper and bronze alloys, including $\mathrm{Sn}, \mathrm{Zn}$, and $\mathrm{Pb}$ [28-30]. Despite the declared interest in meeting the needs of the restorers and searching for a material suitable for the conservation needs, the attention on the hazardousness of BTA (Figure 2), which is toxic, was instead considered at the beginning.

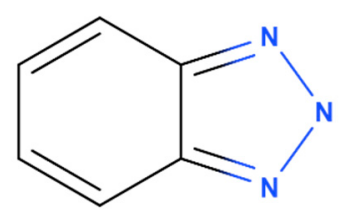

(a)

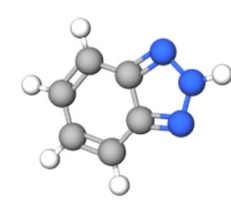

(b)

Figure 2. 2D (a) and 3D (b) chemical structure of benzotriazole (BTA).

One of the first tests on the effectiveness of these compounds on bronze specimens covered with artificially induced patina layers has been conducted by K. Rahmouni and collaborators [25]. In this work, the authors compared [28] the effectiveness of BTA, bi-triazole (BiTA), and amino-triazole (ATA) on bronzes coupons. Cyclic voltammetry highlighted the protection properties of BiTA on coated and uncoated samples. Here, the decreasing of the current indicated the increasing of the protective effect of the natural patina, whereas the electrochemical response results were higher when BiTA was applied on the metal surface, highlighting the protective behaviour of this compound. BTA resulted to be the best corrosion inhibitor when compared with BiTA and ATA, as demonstrated by the electrochemical impedance spectroscopy (EIS) results. After carrying out the experiments on modern specimens, the authors tested the coating on archaeological samples. The ancient coins were immersed into a solution of $0.2 \mathrm{~g} \mathrm{~L}^{-1} \mathrm{Na}_{2} \mathrm{SO}_{4}+0.2 \mathrm{gL}^{-1} \mathrm{NaHCO}_{3}$ acidified at $\mathrm{pH} 3$ for the corrosion test, adding $10 \mathrm{mM}$ of $\mathrm{BTA}$, BiTA, and ATA on the surfaces of different coins. The immersion was carried out for $1 \mathrm{~h}$ and they did not find any aesthetical changes on the surfaces. The EIS experiments were repeated, and it was detected an increasing of the impedance modulus for the coin treated with BTA, meaning that BTA coating also acts as the best protective layer on archaeological surfaces, whereas the other samples showed lower values in terms of impedance [29-33].

Despite the extensive use of BTA in conservation science, it does not have a unique reported protocol-BTA has been used in both alcohol and water solution (1\%-3\% in solution), employed alone or in combination with acrylic resins, applied with a paintbrush or by soaking depending on the object shape. The oxidation state of the metal surface greatly influenced the effectiveness of BTA application and explained the inconsistency of some results reported in literature when this compound was applied on archaeological artefacts. In this regard, Kosec et al. [27] tested different coating recipes based on BTA on copper and bronze specimens with different corrosion patina, associated by the authors with green and brown compounds. Preventively, the corrosion tests were performed on bare bronze without any coating, showing that the corrosion current density was higher for the green patinated bronze $\left(36.3 \mu \mathrm{A} \mathrm{cm}^{-2}\right)$ as expected. The bare bronze had a current density of $3.16 \mu \mathrm{A} \mathrm{cm}{ }^{-2}$, while the one characterized by brown patina had a density of $16.1 \mu \mathrm{A} \mathrm{cm}^{-2}$. The low current density of bare and brown bronze indicated that these types of compounds limit the flow of current, protecting the metal substrate. On the contrary, high current (recorded for the green patina) means that it easily flows through the sample, denoting a fast corrosion of the metal. The potentiodynamic and the impedance results of this work are summarized respectively in Tables 2 and 3. This research highlights that in the case of noble patina (bare bronze and brown patina), the corrosion inhibition and the overall protection of the coating worked in both recipes. The corrosion inhibition was more difficult in the case of the green patina, where the protection effect is limited only at the initial stage of the corrosion 
process. However, Kosec et al. [27] demonstrated the effectiveness of BTA as a corrosion inhibitor and its potentialities when added into a protective coating.

Table 2. Results of potentiodynamic measurements from Kosec et al. [27] when the corrosion current of coated samples was compared with non-coated ones. The arrow $(\Downarrow)$ indicates the decrease of the corrosion current density and thus the protective properties of the coating.

\begin{tabular}{cccc}
\hline & Bare Bronze & Brown Patina & Green Patina \\
\hline 3\% BTA + ethanol & $\Downarrow$ & $\Downarrow$ & No improvement \\
$\begin{array}{c}\text { Paraloid B44 + 3\% BTA } \\
+ \text { carnauba wax }\end{array}$ & $\Downarrow$ & $\Downarrow$ & $\begin{array}{c}\text { Protection only in the } \\
\text { anodic part }\end{array}$ \\
\hline
\end{tabular}

Table 3. Results of impedance measurements from Kosec et al. [27]. The enhancement of the protection refers to the comparison with untreated samples.

\begin{tabular}{|c|c|c|c|}
\hline & Bare Bronze & Brown Patina & Green Patina \\
\hline $3 \%$ BTA + ethanol & $\begin{array}{l}\text { Protection enhanced of } \\
\text { factor } 10\end{array}$ & $\begin{array}{l}\text { Protection enhanced of } \\
\text { factor } 6\end{array}$ & No protection \\
\hline $\begin{array}{c}\text { Paraloid B } 44+3 \% \text { BTA } \\
\text { + carnauba wax }\end{array}$ & $\begin{array}{l}\text { Protection at the initial } \\
\text { stage }\end{array}$ & $\begin{array}{c}\text { Similar to } 3 \% \text { BTA + } \\
\text { ethanol }\end{array}$ & $\begin{array}{c}\text { Protection at the initial } \\
\text { stage }\end{array}$ \\
\hline
\end{tabular}

From the 2010s, the problem of using BTA in conservation of $\mathrm{CH}$ was emphasised by the European Union health directives, and the use of some chemical substances in restoration and preservation became more stringent. BTA and its derivatives should be limited and surpassed, and the need to replace them with non-toxic inhibitors led the recent research to test the applicability of other chemicals that are eco-sustainable for humans and the environment. Although BTA is still used in the research coatings for $\mathrm{CH}$ metals thanks to its inhibiting and transparent proprieties, we highly retain the fact that the use of these substances should be surpassed in favour of non-toxic forms.

\subsubsection{Silanes and Fluoropolymers}

Silane compounds (an inorganic compound with chemical formula $\mathrm{SiH}_{4}$ ) are one of the most diffused class of coating, proposed as an alternative to benzotriazole. Silanes have been introduced as a promising coating thanks to some of their properties required in conservation field-they are hydrophobic, transparent, and corrosion-inhibitors. Coatings forming metal-siloxane (M-O-Si; $\mathrm{M}$ is for metal) or siloxane ( $\mathrm{Si}-\mathrm{O}-\mathrm{Si}$ ) are capable of bonding to metal surfaces through covalent interaction, as they are applied in hydrolysed form (Figure 3). It follows that the formation of homogeneous and compact silane film depends on the physico-chemical properties of the metal surface (i.e., type of alloy, roughness), which makes their application more challenging in comparison to BTA or acrylic resins. In order to improve the adhesion of this coating, the silane films are often applied as multilayer film, in which the first layer provides good adhesion to the metal surface, the second the protection, while the outer faces the environment [34,35].

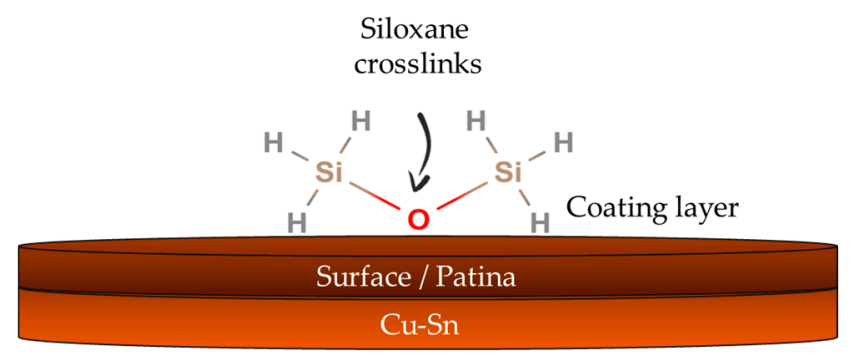

Figure 3. Siloxane cross-linking on the surface of a bronze sample. The mechanism allows the coating to adhere on the metal surface. 
Several studies aimed at improving the performances of silane coatings in order to propose them in substitution to BTA and derivatives. Amongst the most diffuse silane coatings in conservation science, there are the 4-methyl-1-(p-tolyl)-imidazole (TMI), 2-mercapto 5-R-acetylamino-1,3,4-thiadiazole (MAcT), and 3-mercapto-propyl-trimethoxy-silane (PropS-SH). Many of the thiadiazole and imidazole derivatives show a high inhibiting efficiency against bronze corrosion on patinated bronze in artificial acid rain, but their effectiveness is time-dependent and their performances are significantly lower than that of BTA [30,36,37]. For example, Muresan et al. [37] verified the effectiveness of MAcT or TMI in protecting bronzes covered with patina. The authors based their work on their previous experiences on corrosion inhibitors [38]. Muresan and co-authors reproduced a pale blue to green patina on top of $\mathrm{Cu}-6 \mathrm{Sn}$ (in wt \%) bronze, which mimics the one of ancient bronzes. The artificial patina, electrochemically formed on several specimens, was then protected with TMI, PMI (10mM1-phenyl 4-methyl-imidazole), MAcT, and 1mM 2-mercapto 5-R-amino-1,3,4-thiadiazole (MAT). The polymers used in this work with their IUPAC (International Union of Pure and Applied Chemistry) name and structure are reported in Table 4. The authors used both potentiodynamic and EIS experiments in order to evaluate the protection effectiveness of the coatings. In particular, EIS was performed at different immersion periods of the sample into the corrosion test solution $\left(0.2 \mathrm{gL}^{-1} \mathrm{NaHCO} 3+0.2 \mathrm{gL}^{-1}\right.$ $\mathrm{Na} 2 \mathrm{SO} 4$ at pH 5) adding $1 \mathrm{mM}$ MAcT and evaluating the obtained capacitance and resistance data. The experiments were carried out for determining the protectiveness over time-MAcT showed the best performance, whereas PMI was efficient only during the first part of the corrosion tests, and after 3 days it significantly reduced its inhibitory effects. In the study of Muresan and collaborators, TMI gave interesting results on bronze specimens, as it remained stable for the whole period of the experiment. Moreover, it enhanced the auto-protective properties of the patina. The general conclusions of the authors were that the protection of TMI and MAcT resulted lower than BTA, but they have the advantage of being soluble in aqueous medium.

Table 4. Polymers used by Muresan et al. for protecting bronzes.

Polymer
PMI
1-phenyl-4-methyl imidazole Name
TMI 2-p(tolyl)-4-methyl imidazole
MAcT 2-mercapto-5-R-amino-1,3,4-thiadiazole
MAT

Among silanes, 3-mercapto-propyl-trimethoxysilane (PropS-SH, Figure 4) has the most interesting protective properties for copper and bronze. Prop-SH can protect bronze, reducing the formation of corrosion products as well as the loss of materials due to the corrosion process itself $[33,39]$. PropS-SH film applied to gilded bronzes effectively inhibits the growth of corrosion products in the 
interlayer between the bronze and gold, which can cause the detachment of the gilded layer. Recently, a PropS-SH coating was proposed as a non-toxic alternative to Incralac, a toluene solution of an acrylic resin containing BTA, used in restoration especially on outdoor bronzes [40]. Balbo et al. [33] studied PropS-SH and its differences with Incralac. The authors dissolved PropS-SH into 90/5/5 v/v ethanol/water/PropS-SH solution (hydroalcoholic) acidified to $\mathrm{pH} 4$. The solution was used after $24 \mathrm{~h}$ of hydrolysis. Incralac was applied by dip coating method as well as spray coating using, in this case, $3 \mathrm{wt} \%$ solution in ethyl acetate solvent. For both PropS-Sh and Incralac, the dip methodology consisted in $1 \mathrm{~h}$ of immersion of the sample in the coating solution and a thermal treatment at $50{ }^{\circ} \mathrm{C}$ for $24 \mathrm{~h}$, reaching different specific weights (around $1.6 \mathrm{~g} \cdot \mathrm{m}^{-2}$ and $5.6 \mathrm{~g} \cdot \mathrm{m}^{-2}$ ) and thickness. The effectiveness of the coating was tested with electrochemical measurement building an appropriate cell for these samples. The ageing of the coating was evaluated after the exposure in the climatic chamber and the dropping test. The EIS experiments revealed that PropS-SH on bronze samples has a resistance of one order of magnitude values higher than uncoated samples. In all the experiments, the resistance values of PropS-SH were comparable with the ones of Incralac, suggesting that both coatings applied with dip methods lead to good protection. On the other hand, the spray coating seemed more effective in the case of PropS-SH, as it gave the possibility of reaching a higher thickness. The analysis carried out with FTIR and XPS detected the formation of thiolate $(\mathrm{Cu}-\mathrm{S}-\mathrm{C})$ bonds due to the condensation of $-\mathrm{SH}$ groups in the silane molecule of PropS-SH and the formation of $\mathrm{Cu}-\mathrm{OH}$ groups on the metal surfaces that contributes to the adhesion of the coating on the surface. In addition, SEM images of Incralac and PropS-SH of Masi et al. [40] clearly showed the adhesion and the microstructure of both coatings when applied on the surface.

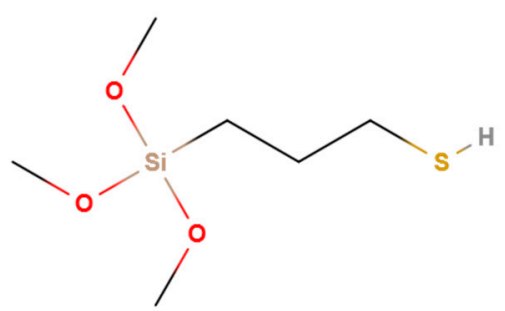

(a)

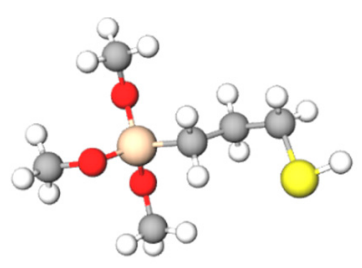

(b)

Figure 4. 2D (a) and 3D (b) chemical structure of PropS-SH (3-mercapto-propyl-trimethoxysilane).

These experiments evidenced that PropS-SH can penetrate better into the metal when applied by spraying, homogeneously covering the surface, whereas Incralac does not show these properties. The higher protective action of PropS-SH with respect to Incralac is due to its ability to form a continuous and homogenous protection layer, as well as a good UV resistance, with little change in colour with age. Moreover, PropS-SH reduces the cathodic and anodic currents (then having a protective feature against corrosion), showing a very promising protective property. These first investigations opened the possibility in using this product for metals exposed in an outdoor environment, even if other factors (such as UV, thermal cyclic) should be considered.

In general, the main advantages highlighted in the literature about the application of silane coatings regard their stability under light exposure, hydrophobicity, and transparency, all characteristics that meet the aesthetic needs in conservation science [21]. The aging tests demonstrated that the colour of the coating is stable over time, particularly after 28 days of immersion in artificial concentrated acid rain. Aufray et al. [41] compared the adhesion proprieties of commercial Incralac with PropS-SH, sol-gel, and silane coatings. The adhesion of Incralac on bare bronze substrate was the most promising, even though when the metal substrates underwent artificial ageing, the results obtained were quite different. In this case, in fact, silane coatings showed the best behaviour in terms of adhesion. Moreover, when the bronzes showed a complex layered structure, the adhesion problems were not so easy to 
solve for all the polymers employed. The protection is influenced by the method of application, the surface roughness, and the type of patina.

A short discussion has to be dedicated to fluoropolymers, which are often associated with silane coating. Fluoropolymers have proven to be optimal for protection, showing good water repellence and photostability, even though low adhesion to metal substrate is often reported [42]. As the name of this class suggests, these polymers are characterized by C-F bonds, which are responsible for the high photostability of the fluoropolymers, especially when compared with those of the $\mathrm{C}-\mathrm{H}$ bonds. Among fluoropolymers, polyvinylidene (PVDF) is the form that has attracted research attention because it shows good durability and chemical resistance. PVDF is a hexafluoropropylene-vinylidine fluoride copolymer and can be dissolved in acetone. Research has highlighted that the adhesion-on metals as well as stones-is the main problem with fluoropolymers $[38,40,41]$. This is usually enhanced by adding other components to the polymer coating. Usually the acrylic polymers (such as Paraloid B-44) are used to increase the adhesion on the substrate, but the low chemical reactivity of PVDF makes its application difficult [42-45]. Another problem encountered with fluoropolymers is their insolubility in common solvents, and their removal can cause safety problems for the environment and for the operator. These are the main reasons why nowadays fluoropolymers are usually modified with other polymers and/or nanoparticles (vide infra).

One remarkable example of application of fluoropolymers regards their combination with sol-gel silica. Bescher and Mackenzie [46] employed 3-glycidoxypropyltrimethoxysilane (GPTMS) with methyltrimethoxysilane (MTMS) on copper alloy. These compounds have the advantage of cross-linking the inorganic part $(\mathrm{Si}-\mathrm{O})$ and the organic part. This mechanism is permitted by the opening of the epoxy ring, allowing the coating to adhere to the surface, and being useful for different substrates. It is of note that even if sol-gel coating has been extensively applied for the protection of other materials of cultural interest, such as stones and glass, thanks to its high mechanical and UV resistance and hardness, its application on metal objects has not taken hold due to the low anti-corrosion properties and the need to mix them with other compounds [47,48].

Siloxanes and fluoropolymers have been proven to be a good alternative to BTA thanks to their protection proprieties and stability over time. For the former, the interaction with the metal surface, thanks to their affinity with transition metals, ensures adhesion with the substrates. It is necessary to take into account, however, that these formulations must be synthesised and applied by highly specialized operators. In the same way, their removal must be studied and performed with caution, especially when they are applied on archaeological artefacts. On the other hand, even if fluoropolymers have been applied on metals, at present, they do not represent the best choice for tackle corrosion issues, and other formulation should be investigated. However, the research is turning to new materials and the nanotechnologies are playing the major role, as explained in the next paragraph.

\subsubsection{Nano-Composites}

The diffusion of nanotechnologies in material science and chemistry has influenced the concept of protective coating for $\mathrm{CH}$ as well. Some studies report the introduction of nanocomposites in coating film to improve transparency, resistance, and anti-fungal barrier. Various nanomaterials have been employed in the last years, extensively on stone surfaces and in combination with sol-gel on glass. On metal alloys, they remain at a preliminary stage, and here we report the most significant nanomaterial application, evidencing their potentiality and the limits still present in the methodology.

In 2017, Faraldi et al. [49] proposed the use of nanostructured diamond-like carbon (DLC) coating as hydrophobic barrier on bronze sample. The main question in this case regards the preservation of the aesthetic aspect of objects. The Atomic Force Microscopy (AFM) analysis assured that no morphological differences were detected after the coating deposition on the copper alloys. The coating thickness was evaluated at about $200 \mathrm{~nm}$, with a slight increase in the roughness value between the copper alloy $\left(r_{\mathrm{q}}=0.83 \pm 0.04 \mathrm{~nm}\right)$ and the DLC-coated alloy $\left(r_{\mathrm{q}}=1.58 \pm 0.34 \mathrm{~nm}\right)$. The elemental analysis conducted with SEM-EDS demonstrated that the presence of DLC coating significantly reduces the presence of 
chlorine after aggressive treatments with respect to the un-coated sample. Moreover, the DLC coating showed very good reversibility by means of oxygen plasma etching. Raman spectroscopy carried out on the specimens where the coating was removed, displayed no extraneous compounds on the surface, demonstrating that the coating can be removed with any modification to the surface. The negative aspect related to diamond-like carbon coating stays in the preparation of the protective layer, which is deposited by plasma-enhanced chemical vapour (PECVD). The method is highly limitative for two main reasons: (i) the dimension of the chamber limits the possibility of depositing the coating on large objects (around $40 \times 50 \mathrm{~mm}$ and a diameter of around $200 \mathrm{~mm}$ ) and (ii) the application of the coating is not possible without the proper equipment or by non-expert users.

In the same years, layered double hydroxide (LDH) nanocarriers were proposed as an effective way to slow down coating photodegradation. Salzano de Luna et al. [50] investigated the problem of photo-ageing of the 2-mercaptobenzothiazole (MTB) in polyvinyl alcohol coating under UV irradiation. In order to limit its photodegradation, the authors encapsulated the MBT into LDH nanocarriers, obtaining in this way a protective film with good anti-corrosion action and improved resistance to photo-degradation. In order to evaluate effectiveness of LCH against photodegradation, the absorbance value of MTB coating exposed to UV was measured as an indicator of coating ageing. According to the authors, the decrease of absorbance indicates the decomposition of the heterocyclic inhibitor when the protective film is under UV radiation. In the case of single MTB, the photo-ageing was faster with respect to the photo-degradation detected when the inhibitor was placed into LDH nanocarriers. More importantly, they obtained similar results in terms of photo-ageing efficiency of the coating when it was exposed in the indoor environment, proposing this combination also for closed areas such as museums.

Nanomaterials are usually inserted in a containment matrix; in this sense, the rise of nanomaterials in the research allowed for the opening of other possibilities for sol-gel coatings. An in-depth description of sol-gel coating is given in Section 3 on historical glass, as it has been largely used on vitreous materials. Here, we mention the work of Kiele et al. [51], in which the authors introduced methyl groups as silica modifiers for improving the hydrophobicity of the coating. In this case, the coating is prepared with tetraethylorthosilicate (TEOS) as a precursor of nanosilica films, a mix of $\mathrm{SiO}_{2}$ sol solution with trimethylchlorosilane (TMCS) and hexamethyldisilozane (HMDS). They followed two forms of preparation and coating application on the substrate: (i) the colloidal nanosilica were modified in liquid phase carrying out the-dip coating on substrates, and (ii) the silica coating obtained on the copper substrates were treated with TMCS and HMDS. The aged samples suffered photochemical degradation, but the hydrophobicity remained stable over time according to contact-angle measurement. The potentiodynamic results supported the hypothesis that HDMS acts as good corrosion barrier, preserving the metal underneath.

The attempts in nanocomposite application on metals and copper alloys are restricted when compared to the available technology. A completely different situation has been found for stone materials (vide infra) where the application of nanocoating found large diffusion because of the specific requirements of the substrate. On metal alloy, nanotechnologies have not been able to replace traditional coating methods for improving stability and inhibitor efficiency. Despite this, we strongly believe that the research in this field is desirable, especially for replacing methods that are dangerous for health and the environment. At the moment, the research is at a crucial point in which the first applications have been tested and the capabilities of nanotechnologies have been demonstrated. We are aware, however, that new frontiers are going to be explored and the new generation materials will make a difference for the protection of $\mathrm{CH}$.

\subsubsection{Biofilms and Biopolymers}

A great leap forward has been made in the last few years around bio-based corrosion inhibitors and green coatings. These novel applications are still sporadic and do not belong to the established conservation methods, yet deserve to be mentioned and discussed. In fact, the prospect of having "green" alternatives is certainly a solid possibility for the future, and this topic needs to be discussed 
in the present coating research. To date, some attempts have been made with products extracted from plants or organisms [52] or made of amino-acids [53-55], and there have been studies on their anti-corrosive properties, even though so far no experiments on real artefacts have been conducted. A significant example in the field of biofilms is the use of fungal strain to combat the corrosion processes. The possibility of using fungal species on bronze lies on the fact that they can produce oxalic acids useful in converting the copper corrosion compounds into stable and less soluble products that do not participate in the corrosion reactions. Albini et al. [56] obtained a bio-patina based on Beauveria bassiana, dispersing the fungal species in a water solution with nutrients and jellifying agents. After 2 weeks of application, the bio-patina was removed, and the samples cleaned from fungal residues. The authors immersed the corroded samples in BTA solution for $24 \mathrm{~h}$ and 14 days. The characterisation of both types of coated samples was carried out through optical microscopy, SEM, and FTIR spectroscopy. Cu-BTA complexes were detected by FTIR analysis, as well as the copper oxalates, which were found in the bio-based samples. Atacamite $\left(\mathrm{Cu}_{2} \mathrm{Cl}(\mathrm{OH})_{3}\right)$, one of the most dangerous compounds in bronze disease, was also found, but a decrease in concentration after the biofilm treatment was highlighted. Moreover, EIS showed that the biofilm treatment was more effective against corrosion, as the absolute impedance value was found greater of one order of magnitude in comparison with the untreated and BTA-treated samples. The positive effects reported for the biofilm was its capability in converting almost all the atacamite into a homogeneous layer of copper oxalates, which has the secondary consequence of inhibiting the corrosion of metal. Table 5 summarizes the film thickness and the products detected on the samples treated with BTA-24 h, BTA-14 days, and bio-coating.

Table 5. Summary of the thickness and compounds detected on the samples treated with the coatings. Intense detection: $\boldsymbol{V} \boldsymbol{V}$; normal detection: $\boldsymbol{V}$; low detection: $\downarrow$; not detected: $\boldsymbol{X}$.

\begin{tabular}{cccc}
\hline & BTA-24 h & BTA-14 Days & Bio-Based \\
\hline Thickness $(\mu \mathrm{m})$ & 15 & 33 & 15 \\
Blackening & $\checkmark \checkmark$ & $\checkmark \checkmark$ & $\checkmark$ \\
Copper oxalates & $\checkmark$ & $\checkmark$ & $\checkmark \checkmark$ \\
Atacamite & $\checkmark$ & $\checkmark$ & $\downarrow$ \\
BTA-Cu & $\downarrow$ & $\downarrow$ & $x$ \\
\hline
\end{tabular}

Within the green chemical approach, more attention is given to biopolymers, especially to the ones from renewable resources. One example is poly(lactic acid) (PLA), with production starting from totally renewable materials (lactic acids), which is biodegradable. Giuntoli et al. [57] presented an innovative PLA-based polymer useful for the protection of metallic surfaces according to their previous experience on PLA combined with fluorinate alcohols employed for protection of stones [58]. On metallic surfaces, fluorine was substituted with a benzotriazole (BT) moiety, and the end-capped PLA-BT polymer was tested on modern aged bronzes, bare and patinated. The polymer was applied on metallic specimens, its growth was monitored with NMR, and its protection effectiveness evaluated after the ageing of the samples. Differently from acrylic polymers, PLA presents a good colour stability under photochemical and accelerated thermo-hygrometric ageing. However, the research focused simply on the proposal of PLA as novel coating, whereas it completely lacked any evaluation of the anticorrosive efficiency, which instead would be fundamental for considering PLA as a promising material for bronze protection.

Giuliani et al. [59] tested the protective effectiveness of chitosan on copper-based alloys. Chitosan is a natural polymer, obtained by the partial deacetylation of chitin under alkaline conditions or by enzymatic hydrolysis. The authors used this polymeric matrix for embedding BTA and MTB as corrosion inhibitors in order to reduce the leaching of those toxic compounds in the environment. They obtained a long-lasting protective film. Apart from transparency and compatibles quality of this biopolymer, the use of chitosan is strongly recommended for its eco-friendly and biodegradation properties. The research showed that the preparation of the biofilm is a key point in the effectiveness 
of the protection-a plasticizer agent (glycerol) is needed in order to obtain the best film quality and the results evidence that the application of chitosan-based coating can improve the protective barrier against environmental agents, also allowing the achievement of superior performance with respect to BTA alone.

As stated before, biopolymers are among the most interesting materials for $\mathrm{CH}$ protection, but the chemical proprieties and stability over time have to be deeply investigated. In the authors opinion, the use of biopolymers should rule out the addition of toxic compounds (such as BTA), evaluating the possibility of testing the anticorrosive ability of other eco-friendly or natural products.

\subsection{Silver and Iron}

Silver and iron represent a class of metals widely diffused in ancient times. However, the research dealing with the protection of these materials is still limited compared with that of copper and bronzes. They are subject to diverse corrosion processes with respect to that previously mentioned for copper alloys, and different protective coatings have been developed for these metallic surfaces. In archaeological sites, silver is mainly found in decorative objects and coins, whereas iron and its alloys are often associated with weapons.

Historically, silver has been commonly combined with copper, in Ag-Cu alloy, varying the content of $\mathrm{Cu}$ depending on the object value. It is worth stressing that the lower purity of the alloy means a higher corrosion tendency. In fact, the Ag-Cu corrosion regards mainly copper, as it is a less noble metal, although the formation of copper oxide patina can have a self-protective function. Coating films developed for copper and bronze have been demonstrated as not always being suitable for $\mathrm{Ag}$ or Ag-Cu alloy. This has been verified, for example, in the case of plasma polymer coating in a work conducted by Favre-Quattropani and co-authors [23]. The plasma polymer coating did not show good adhesion on silver because of the diffusion of Ag ions into the coating itself, possibly activated by the $\mathrm{H}_{2}$ plasma treatment. On the other hand, the protection against sulphide compounds was shown to be good when coated silver was exposed to an aggressive environment. The coated platelets showed blackening only after a very prolonged exposure.

The use of nanotechnologies has also been recently explored for silver protection by Grassini et al. [60]. $\mathrm{Al}_{2} \mathrm{O}_{3}$ nanoparticles were used on silver specimens in order to improve the corrosion protection of an acrylic coating based on Paraloid B72. [61] The possibility of improving the characteristics of Paraloid B72 with nanoparticle suspension, attracted the attention of the researchers [62]. In the case of silver protection, the authors used nano-alumina $\left(\mathrm{Al}_{2} \mathrm{O}_{3}\right)$ pigmented acrylic resin suspension in order to protect the metal substrate from corrosion as well as preserve the aesthetic side of the artwork. The results obtained by Grassini and collaborators were promising, even if the deposition of the polymer coating was complex (made by plasma-enhanced chemical vapour deposition), and this method should be further improved.

Regarding iron, it is of note that its corrosion involves complex chemical reactions, and one of the main problems regards the formation of chlorine compounds. Slowing down the corrosion of iron is challenging, and studies mainly focus on its protection, as the first attempts on corrosion inhibition were not rewarding. A brief parenthesis on the interesting work of Cano et al. [63], who tested the effectiveness of Paraloid, Poligen (an ethylene copolymer), and Reinaissance (acrylic and polyvinyl acetate polymers) coatings by doping them with four different corrosion inhibitors, namely, triazoles, an ammonium salt of tricarboxylic acid, a calcium sulphonate, and a bis-oxazoline called Alkaterge-T on steel. The results of the study demonstrated that adding the corrosion inhibitors into the coating does not provide significant improvement in slowing down the corrosion itself. However, the complexity of iron corrosion is shown in the difficulties of the development of an adequate coating.

Another interesting piece of research displayed the possibility of protecting iron using Paraloid B72 with caffeine (1,3,7-dimethylxanthine) or nicotine pyridine (S)-3-(1-methylpyrrolidin-2-yl) as corrosion inhibitors [64]. The experimental results were crossed with statistical analysis. The main purpose was monitoring the corrosion induced by humidity, as well as the response of the coating under different 
environments. According to the authors, Paraloid B72 and nicotine gave the best results in terms of corrosion protection. Both nicotine and caffeine reduced the humidity-Paraloid B72 interactions, protecting the metal substrates. The study of natural compounds such as nicotine or caffeine for iron protection is interesting, but the use of an unsuitable polymer such as Paraloid B72 should be limited in favour of new formulations.

A relevant case-study is represented by the underwater iron finds, published by Ashkenanzi and collaborators [21]. When artefacts are removed from the sea, they must adapt to new environmental conditions, and this can cause a deep stress of the material, accelerating the corrosion. These kinds of objects need special attention due to the severe conditions they suffered. Aiming at preserving the iron artefacts retrieved from shipwrecks, the authors developed a coating based on silane monolayer covered by a thicker wax layer. As illustrated in the case of copper alloys, silane coatings are catching the attention of researchers because of their significantly positive characteristics for metal conservation. The work of Ashkenanzi et al. [21] tested the silane coating both on modern specimens and ancient ones. The characterization of the ancient artefacts was carried out along with the need to apply the coating above it, testing the effectiveness of the protection. The corrosion test showed an important inhibition effect and a self-healing characteristic of the coating, making this material very promising.

Different observations should be made for brass objects, which deserve to be mentioned, although coating exclusively developed for this kind of alloy have not been investigated yet. The research on this material is mainly directed on the characterization of archaeological objects and the study of patinas and corrosion. The constraints lie on several issues: (i) the mechanisms of brass corrosion are not yet fully understood, even for modern alloy; (ii) the orichalcum objects are less frequently found in archaeological excavation and therefore it is more complicated to study the processes of degradation that occurs during the burial period or in the outdoor environment; (iii) when it is possible to study these kind of objects, the focus is still on their manufacturing, as the production of this alloy in the past involved elaborate processes that are not fully elucidated. After a more complete description of these important aspects, the development of protective coatings suitable for brass would be affordable.

\section{Glass}

Glass principally suffers because of atmospheric weathering, pollution, and acidifying gasses (Figure 5). The progression of superficial reactions with environmental agents leads to noticeably visible aesthetic changes of the glass. The primary visual modifications are associated with the tendency of the surface to become opaque or iridescent, which consequently affects the transparency of the glass itself, and induces the propagation of micro-cracks on the superficial layer [65]. The importance of these effects, the resistance and durability of glass against weathering agents, are mainly determined by its chemical composition, which depends on the geographic provenance and production period of the material. Historical glass is composed principally by silicon oxide with a lower amount of other oxide compounds, such as potassium, sodium, and calcium oxide. Over time, the content of silica has reduced in favour of an increased amount of potassium and calcium, and this has implied a lower chemical stability, evident especially on medieval glass [66,67].

The corrosion of the glass surface has been widely studied, especially in relation to the presence of aqueous acid solutions-the main corrosion mechanism is associated with the ion exchange process between metal ions of the glass and $\mathrm{H}^{+}$from the acidic solution (Figure 6) [66,67]. Because of superficial ion exchange, the outer layer of the glass becomes enriched with hydrogen, whereas the silica core remains unaltered. Afterwards, hydrogen reacting with oxygen can lead to condensation, and the subsequent water evaporation can induce cracking at the glass surface. This represents the worst stage of degradation for a glass object. It follows that the whole process of corrosion is induced by an acidic environment and relative high humidity of the ambience in which the glass is placed. The additional presence of acidifying gases such as $\mathrm{CO}_{2}, \mathrm{SO}_{2}$, and nitrogen oxides $\left(\mathrm{NO}_{\mathrm{x}}\right)$ can accelerate the ion exchange process, and the interaction with these compounds must be primarily avoided. 


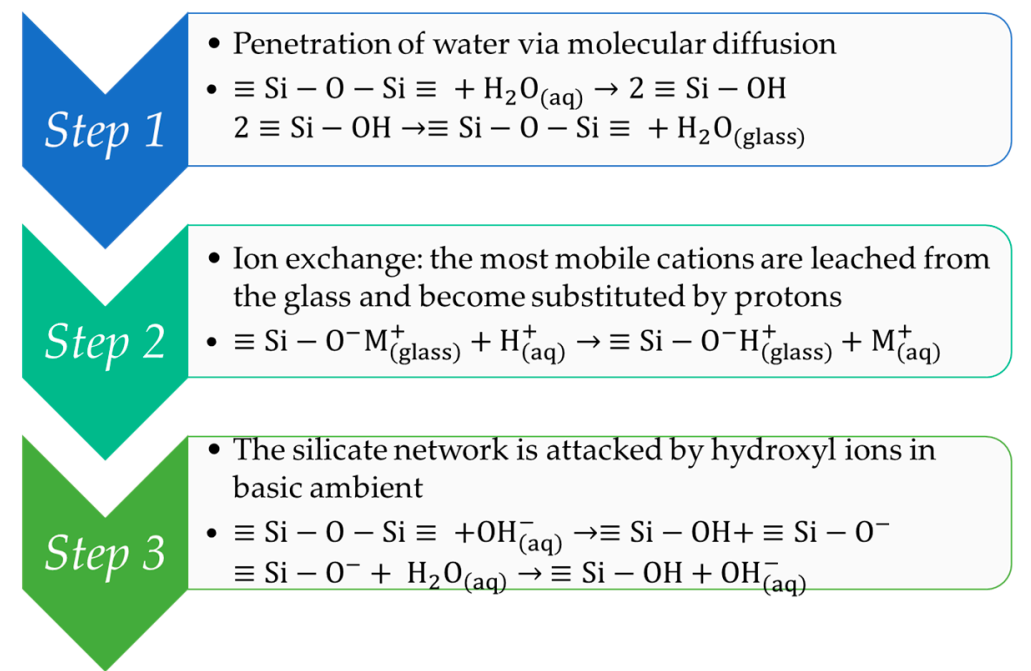

Figure 5. Progressive chemical reactions that lead to the corrosion of glass induced by aqueous environment.

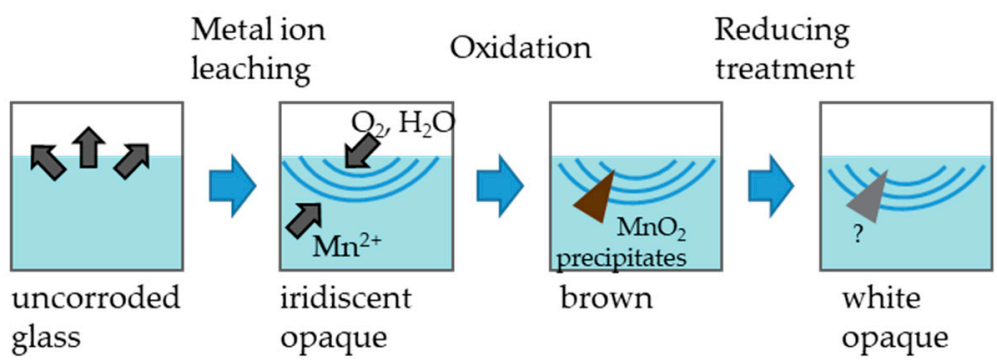

Figure 6. Example of surface corrosion in Mn-based glass, which cause the formation of iridescent patina and deposition of brown $\mathrm{MnO}_{2}$ precipitates.

Amongst historical glass, stained glass suffers particularly from the interaction with external agents because they are unavoidably exposed to the atmosphere and sunlight. Passive protection, such as outdoor glazing, is sometimes applied in order to reduce the opacification rate of these expanded glass surfaces $[2,3,68]$. The outdoor glazing acts as secondary screen and is posed the external face of the stained glass. Although it is estimated that the use of external glaze initially reduces the impact of the ambient and weathering, it has negative effects on the glass colour appearance because of the decreased transmission of light, and of the the condensation, which accumulates in the interspace between the glazing and the glass [2].

When possible, for a more efficient protection, the direct application of chemical inhibitors on top of the glass surfaces is desirable [4,69-72]. In the following section, we discuss and propose the most valuable coating methods tested and employed nowadays on ancient coloured glass, evidencing the potentiality and the drawbacks of some applications.

\subsection{Sol-Gel Films}

The most successful applications in glass protection, which come directly from technological advances, are nowadays represented by sol-gel silica coating. Despite the science of sol-gel dating back to 1824 , the first attempt of sol-gel coating dedicated to $\mathrm{CH}$ was in 1861, when W. von Hofmann [73] proposed ethyl silicate for the consolidation of the deteriorating limestone [69]. This method has been explored on stone, mosaic, and bronze works of art [74,75], although it is on glass that this type of coating has given the most effective results [76].

Sol-gel coating has been proven to be an effective permeable barrier, working well against corrosion. This inorganic film owes its good applicability to its composition; in fact, it is based on 
hetero-polysiloxanes ([ $\left.\mathrm{R}_{2} \mathrm{SiO}\right]_{n}$, where $\mathrm{R}$ is an organic group such as an alkyl or phenyl group), which is known to provide good adhesion to inorganic substrates. The main property that makes this method appreciated for glass materials is its glassy transparency, the moderate working temperature, the possibility of depositing single film by dip or spray coating, and its compatibility with the glass surface [67]. These are the reasons why nowadays sol-gel coating represents a unique choice for artistic glass materials.

The most diffused applications of sol-gel coating on glass are based on tetraethoxysilane (TEOS, $\left.\mathrm{Si}\left(\mathrm{OC}_{2} \mathrm{H}_{5}\right)_{4}\right)$ as a silica precursor (Figure 7). The effectiveness and the resistance against weathering of TEOS sol-gel silica coating on reference glass materials under accelerated ageing conditions and exposure to acid gas have been firstly determined by Carmona and co-authors [75]. In this study, TEOS was used as a silica precursor for the preparation of the sol, whereas other sol components were absolute ethanol (EtOH), acetylacetone (Hacac), diethylene glycol (DEG), and distilled water acidulated with $\mathrm{HCl}$. Thin coatings from the sol were applied on the reference glass by dip-coating with a drawing rate of $11.5 \mathrm{~cm} \mathrm{~min}^{-1}$. Coating densifications were achieved by thermal treatment in an electrical oven, whereas the thickness of the resulting coatings was evaluated around $330 \mathrm{~nm}$ $( \pm 10 \mathrm{~nm})$. The results of these experiments showed a good protective action of the film deposition on top of the glass. In particular, the higher the coating densification temperature, the better the adherence of the coating film to the substrate. Although the use of densification temperature between 250 and $400{ }^{\circ} \mathrm{C}$ has been demonstrated to be effective for a homogenous and uniform sol-gel film deposition in many functional coating studies, it is generally not safe for application on fragile historical glasses. An alternative coating method is to consider cycling depositions of sol-gel at low temperature $\left(60^{\circ} \mathrm{C}\right)$ in order to form a multi-layered structure. This multilayer coating densified at moderate temperature is verified to be more efficient than a single layer coating densified at high temperature for the same time [75].

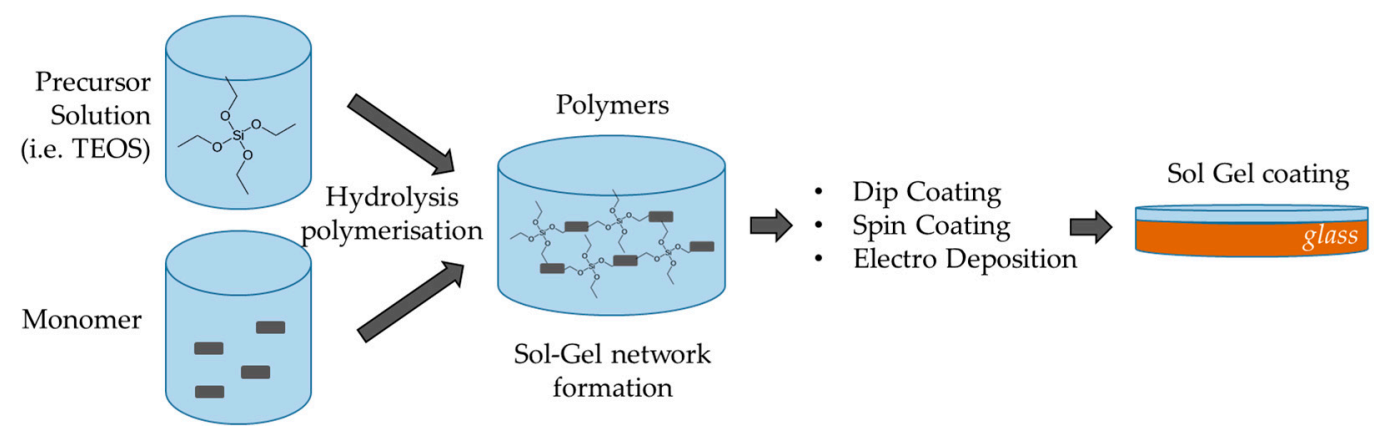

Figure 7. Sol-gel synthesis route.

Densification temperature is considered the main weak point for sol-gel application on $\mathrm{CH}$ objects. The research on possible solutions for applying sol-gel without any heat treatment has been particularly appreciated over time. One proposed method for developing thin films at room temperature employed perhydropolysilazane (PHPS) as a precursor. In fact, this polymer has the advantage of reacting with atmospheric moisture after deposition, producing the typical structure of silica [76]. PHPS has been tested on soda-lime substrates and deposited with dip-coating (dipping $1 \mathrm{~min}$ and extracted at $1.5 \mathrm{~cm} \cdot \mathrm{min}^{-1}$ speed). In this case, the glass coating can be completed under vapours of aqueous ammonia solution at room temperature in 3 days, whereas a temperature of about $45^{\circ} \mathrm{C}$ is required for a quicker deposition $(2 \mathrm{~h})$. Despite some preliminary good results, PHPS coating counts also unsatisfactory applications, and for this reason it has to be used carefully. For example, on original ancient glass tile, an incomplete conversion of PHPS to silica was observed, even when treated at moderate temperature, and additionally a migration of metal ions into sol-gel coating from the substrate was detected. The negative results of this work impacted on the diffusion of PHPS as a silica precursor and produced evidence for the importance of ageing tests for defining the best performing coating [77]. 
Sol-gel silica coatings based on TEOS remains the most facile method for historical glass protection, and for this reason it is most frequently employed in conservation. Despite this, it should be mentioned that it does not always represent the best coating choice. This is the case, for example, on soda-lime and lead silicate glass. The standard acid catalysed solution of TEOS results are inapplicable on these types of glass because the immersion of lead-glass in acid solution causes the change of the surface glass colour [78]. Indeed, lead ions have a large charge-to-radius ratio, which induces a large mobility in the $\mathrm{SiO}_{2}$ network. In sol-gel solution, which usually has a $\mathrm{pH}$ 2, lead ions tend to be leached towards the acid solution and the outer layer of glass becomes depleted in lead and alkaline ions. It follows that the application of such a coating process on soda-lime-silicate or lead-reach glasses leads to the formation of an iridescent patina, affecting the transparency and optical characteristics of the glass and making the coating unsatisfactory. It is worth noting that the reduction of $\mathrm{pH}$ value to a more basic solution would reduce these issues, but the deposition of the protective film would be not adequate. The most outstanding solution to tackle this problem was proposed by Bertoncello and collaborators, who suggested the adoption of a heavy metal as catalyst in the silica glass polymer in order to reduce the ion mobility effect [78]. Sol-gel can be prepared by employing ethanol as a solvent, TEOS as sol-gel precursor, deionized water for the hydrolysis, and hydrochloric acid as a catalyst, with a $\mathrm{pH}$ around 2. Bertoncello and co-authors, with this procedure, produced a coating film on glass by dip-coating, with a dipping rate of $9.0 \pm 0.1 \mathrm{~cm} \mathrm{~min}^{-1}$. The authors performed several tests on soda-lime silicate glasses in order to sustain this idea, and the results confirmed the potentiality of this approach. They demonstrated that even a small amount of heavy metal (in this case lead ions were used) introduced through a precursor solution can be sufficient to start a good two-dimensional polymerization and to reduce ion exchange in soda-lime glass or in poorly durable potash glass [78].

Remarkable complexities for protective coatings are presented by gold mosaic tesserae. A frequent deterioration phenomenon in this kind of mosaic is the detaching of the superficial glass layer from the substrate and the consequent exposure of the gold substrate. The sol-gel coating does not show good results on these surfaces and multilayer protection is evaluated as useless and, in some cases, dangerous because it not perfectly adheres to the metallic surface [79]. The problems of adhesion of sol-gel coating on gold mosaic tesserae require particular attention, and efficient solutions have not been defined yet.

Despite the favourable glassy transparency of sol-gel film, the reversibility of the coating application should be retained as a priority feature in some cases. For example, stained coloured glass can be found decorated with paint, usually dispersed with an organic binding medium and then dried on top of the glass surface through thermal treatment (above $500{ }^{\circ} \mathrm{C}$ ). The stratigraphy and the use of different materials make stained glass difficult to protect, and the consolidation of paint on stained glass is one of the main problems when restoring glass windows. On this and other similar cases, new sol-gel consolidation based on different hybrid organic-inorganic alkyl-alkoxysilane systems are the best protective option. It is of importance to note that good protection and consolidation of historical glass surfaces cannot be made at the expense of the reversibility of the protective treatment, and the penetration of coating into the porous materials must be considered.

\subsection{Hybrid Sol-Gel}

As anticipated, in the last decade, the attention moved from simple silica sol-gel to the development of hybrid sol-gel solutions in order to improve the quality of the coating and its applicability to historical glasses from different times and chemical compositions. Hybrid sol-gel materials are composed of an inorganic silica matrix, in which either organic molecules or inorganic oxides are dispersed. Coating formula are generally designed in accordance with specific application performance requirements, and hereby we report the most relevant tentative and results.

One of the challenges in applying protective coating in the $\mathrm{CH}$ sector is the impossibility of directly translating industrial and technological transport on historical artefacts. Inspired by applications of sol-gel coatings on glass for industrial applications, Carmona et al. [80] considered zirconium 
tetrabuthoxide $\left(\mathrm{Zr}(\mathrm{OBu})_{4}\right)$ in TEOS sol-gel for increasing the resistance of the coating to atmospheric polluted conditions. In fact, the incorporation of $\mathrm{ZrO}_{2}$ is known to increase the alkaline resistance of the coatings, which would be an interesting property also for historical glass. The authors tested various recipes in which TEOS is mixed at different molar ratio with zirconium oxide (0:100, 50:50, and 90:10), and treated with various densification and ageing tests. The attempt of employing $\mathrm{ZrO}_{2}-\mathrm{TEOS}$ at moderate temperature was not satisfying because of the incomplete densification of the coating caused the formation of cracks at the surface of the coating itself. It is worth noting that sol-gel in combination with zirconium in industry is usually treated with temperatures above $400{ }^{\circ} \mathrm{C}$. Moreover, the authors observed an increase of the reflectance of the coating due to an increased fraction of zirconium oxide, which negatively affects the appearance of the glass substrate.

The most successful results on historical glass are represented by hybrid organic-inorganic sol-gel applications. In this case, the protective film can benefit from dual behaviours-from one side, the inorganic part (hetero-polysiloxane) forms strong covalent bonds with the glass surface, whereas the organic fraction (composed by organic functionalities) provides additional properties to the coating film, such as water repellency, oxidation resistance, or crosslinking. In most cases, TEOS is used as a precursor, functionalized with different alkoxides (RO-). One of the most effective water repellents for historical window glasses based on hybrid protective coatings is studied by De Ferri and collaborators [3]. The silica-based inorganic matrix is functionalised with organic chains to obtain a good surface water-repellency and the optimal degree of elasticity of the film to avoid the formation of cracks during the drying process. TEOS was used as precursor in different proportions with silicon alkoxides functionalized with different alkyl groups (octyltri-ethoxy-silane-OTES, hexadecyl-tri-methoxy-silane-HDTMS, and tri-methyl-ethoxy-silane-TMES) and applied on potash-lime-silica that mimics medieval window glass. The coating results are transparent, colourless, and water-repellent, which are the main requirements for considering it as promising for glass coating. Moreover, the authors evaluated a good elasticity of the film with low incidence of cracking and stability under $\mathrm{UV}$ ageing and $\mathrm{SO}_{2}$ corrosion tests.

Other similar tests based on TEOS functionalized with different ratios of organo-functional silane modifier are aimed at optimizing the film coating with different time periods of sol-polycondensation [81]. The best weatherability results were achieved using silica coatings functionalized with long alkyl chains. Compared with commercial hybrid silica products, the methacryloxy (MEMO) functionalized silica coatings in particular display improved homogeneity, elasticity, and barrier properties. These novel sol-gel methods pose a special attention not only to protective action but also to common restoration and conservation practices and to possible in situ application of the methods.

Despite different possibilities of hybrid sol-gel coating having been exploited in the last 20 years for industrial applications [3], the attempts made on archaeological and historical glass are still limited, as reported in the overview made by Bescher et al. [74]. We believe that this is the direct consequence of the short-term stability of many of the treatments, which have been demonstrated as being successful on laboratory mock-up tests, but that has to be frequently monitored on real historical glass pieces because of deterioration reactions induced by environmental conditions. However, the potentiality of the method must be further explored in order to make hybrid sol-gel coating a concrete solution for historical glass protection.

\section{Limestone}

Through history, a variety of stone types have been used for building or artistic purposes. Amongst these, limestone is undoubtedly the most common stone used in the past. Limestone is a carbonate sedimentary rock mainly characterized by calcite minerals $\left(\mathrm{CaCO}_{3}\right)$ and often formed in a marine environment or when calcareous materials are available. Marble and travertine are carbonate rocks as well, but the environment of formation and the chemistry reaction involved are quite different from 
each other. Travertine, a common stone used by Romans, is a carbonate sedimentary rock formed by a chemical reaction. Here, water rich in carbon dioxide percolates through rocks in limestone areas, and it dissolves the limestone becoming saturated. When changes in pressure or temperatures occur, the water releases the carbon dioxide as gas and then the calcium carbonate recrystallize. The final rock is porous, rich in moss. On the other hand, marble is a metamorphic rock in which carbonate minerals have recrystallized under high temperature and pressure conditions. In literature, marble and travertine are usually included in the more general limestone-class of rocks.

The degradation of stone mainly depends on the environment of conservation. Because most of the stone materials are placed outdoors and interact with the atmosphere, carrying out a preventive conservation by the environmental monitoring is limitative. Then, the protection using coatings became essential. Strength, durability, and weathering characteristics of stone are related to its constituent minerals. Calcite, and consequently limestone, is a soft material; besides the chemical alterations that will be described below, it easily undergoes cracking and splitting due to its microstructure and chemistry. Sandstones, on the other hand, may or may not be subjected to deterioration depending on the mineralogy composition, i.e., quartz is very resistant to physical or chemical attack and, thus, very durable. Such rocks are more difficult to scratch, generally have higher compressive strength, and are much more resistant to erosion. Due to the high resistance of sandstone to deterioration, protective coatings are usually developed for limestone rather than sandstone. As a consequence, only few studies are present in the literature on the protection of sandstone. The following chapter will thus be focused on the carbonate-class of rocks, whereas details about sandstone protection can be found in the references regarding the stone protection [82-96].

Recent research demonstrates that environmental pollution is the major cause of limestone degradation, favouring the formation of the black crusts on the surface. Black crusts affect the aesthetic side of the artwork, blackening the surface and endangering the tightness of the monument itself due to structural weakening. In simple terms, this degradation is due to the interaction between the calcareous surface and $\mathrm{SO}_{2}$, particulate matter, and acid rain in the atmosphere [83]. Studies indicate additionally that the composition of the black crusts mirror the composition of the atmosphere [83-85].

The main responsible factor for chemical changes of limestone is $\mathrm{SO}_{2}$. It reacts with the calcite, producing gypsum $\left(\mathrm{CaSO}_{4} \cdot 2\left(\mathrm{H}_{2} \mathrm{O}\right)\right)$ [86]. Gypsum is more soluble and has a very high porosity, which allows the entry of extraneous materials such as particulate matter (PM). PM are particles of the order of micron, mainly produced during combustion reactions and that can operate as intermediary transport of several compounds, especially carbon and metals $(\mathrm{Pb}, \mathrm{Ba}, \mathrm{Cu}, \mathrm{Zn})$, which cause surface blackening $[87,88]$.

Overall, two kinds of damage can be defined: (i) chemical alteration given by the conversion of $\mathrm{CaCO}_{3}$ into $\mathrm{CaSO}_{4} \cdot 2\left(\mathrm{H}_{2} \mathrm{O}\right)$, and (ii) mechanical stress due to the formation of porous gypsum crystallite and the deposition of PM, with a subsequent erosion of the surface. Searle and Mitchell [89] investigated the effects of diesel and coat particulate on Portland limestone, highlighting that the diesel particulate had worse effects on the surface erosion of this material, catalysing the formation of gypsum. The degradation of stone materials is therefore governed by many factors [7]. The conversion of limestone into gypsum is accelerated when compounds such as nitrogen oxides $\left(\mathrm{NO}_{x}\right)$ and other peroxides are present in the atmosphere [90]. Because of the simultaneous contribution of several chemical reactions, the study and the monitoring of the materials exposed outdoors can be very complex.

The presence of water can also be dangerous for the conservation of limestone. Leaving aside the specific problems of monuments such as fountains, historical buildings can suffer from efflorescence and sub-efflorescence due to the crystallization of the salts and the flowing of the water into the walls. This leads to mechanical stress and the growth of microorganisms such as mold into the stone [91]. This phenomenon also makes difficult the development of protective coatings that are not excessively permeable in order to favour the evaporation of water and prevent the stagnation.

Complementary to the slow decay due to polluted environments, bioactivity is another reason for stone deterioration, strictly connected with the presence of water on the surface. In a favourable 
environment (high levels of humidity and light exposure) and with good petrological characteristics (high porosity), microorganisms can proliferate on stone surfaces. Biodeterioration is considered differently from corrosion or erosion, for which the changes are due to a chemical, physical, or mechanical alteration. In the case of biodegradation, in fact, the surface is modified as a consequence of the vital activities of living organisms [92]. This is a very widespread and concerning problem, which involves warm regions as well as continental and cold areas, because of the extreme adaptability of the microorganisms [93,94]. As reviewed by Warscheid and Braams [93] there are several microorganisms that induce the deterioration of stones, and the work collects the common procedures to clean and preserve the materials from these kinds of alterations. Fungi, bacteria, algae, lichens, and protozoa are the first microorganisms that colonize an outdoor surface [93-95]. Their vital activities cause chemical damage on the stone itself. In fact, microorganisms solubilize compounds indispensable for their metabolisms, involving the production of acids that can damage the stone surface and modify the substrate in which they reproduce [96]. On the other hand, they can also penetrate deeply into the surface, changing the colour of the surface itself [97]. As is illustrated in the next of this section, the action of microorganisms is not always suggested as dangerous for historical surfaces, but some studies open the debate about the bio-protection of stone surfaces. The modifications induced by microorganisms can help the protection from other environmental parameters (i.e., pollution), although this will be discussed in detail in Section 4.2., and their activities need to be strictly monitored for avoiding damages. A simplified summary of the effects of the stone degradation is reported in Table 6 .

Table 6. Causes of limestone degradation and its effects on the surface.

\begin{tabular}{cc}
\hline Cause & Effect \\
\hline Pollution & Black crusts \\
& Gypsum formation \\
Water & Erosion \\
& Saline efflorescence \\
Microorganisms & Mechanical stress \\
Plants & Microorganism growth \\
\hline
\end{tabular}

In the next paragraphs we go in-depth into the protective actions employed nowadays on carbonate rocks. As for metals and glass materials, acrylic polymers have been largely tested on limestones as well, whereas the major novelty on stone materials is the development of superhydrophobic and photocatalytic nanocomposites, as well as the investigation of bio-patinas. We present the most recent results, showing evidence of how the research has answered the need of preserving outdoor monuments.

\subsection{Acrylic Polymers}

Starting from the 1960s, commercial acrylic and methacrylic resins have been extensively used in the conservation of $\mathrm{CH}$ [98]. They have been employed for different purposes, for example, in the formulation of paints and adhesives because of their good film and mechanical properties, transparency, and stability, and more recently as surface coatings for consolidation and protection thanks to their good adhesion and water-repellent performance.

Among the wide range of acrylic polymers (Figure 8), polyacrylates and methacrylates $\left(\mathrm{CH}_{2}=\mathrm{CHCO}_{2} \mathrm{R}\right)$ have been frequently used in stone conservation because they exploit both protective and consolidating properties. One of the most famous co-polymers in the last 20 years is Paraloid B72, obtained via free radical polymerization between ethyl methacrylate (EMA) and methyl acrylate (MA). Nevertheless, other homo-methacrylic polymers such as poly(metyl methacrylate) (PMMA), 
and poly(isobulyl methacrylate) (PiBMA), known by the commercial name of Paraloid B67, have been extensively employed, particularly in the protection of stones and frescoes [99].

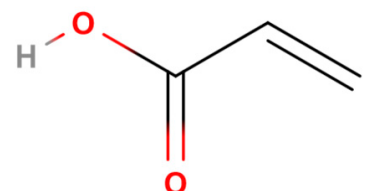

(a)

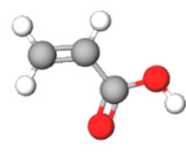

(b)

Figure 8. $2 \mathrm{D}(\mathbf{a})$ and $3 \mathrm{D}(\mathbf{b})$ chemical structure of acrylic acid $\left(\mathrm{CH}_{2}=\mathrm{CHCOOH}\right)$.

One of the most relevant issues associated with the application of acrylic and methacrylic polymers is related to their durability and removability, induced by the tendency of these polymers to photo-oxidize. Favaro et at. [100] reported a detailed comparison of properties under photo-oxidative process of the two most used Paraloid polymers, B72 and B67, and a silicon-based polymer (Dri-Film 104), observing that, in all cases, strong polymer modifications lead to the impossibility of removing it from the stone and to a decrease of the consolidating/waterproofing behaviour.

Because of this irreversibility of the coating, several studies focused their attention on the investigation of the stability of acrylic polymers under thermal ageing, and on photo-degradation reactions. It has been defined that the structures formed as a consequence of oxidation, occurring under either artificial solar light irradiation or thermal ageing, are similar in both acrylic and methacrylic polymers-scission reactions prevail when the ester side group is short, whereas when ester side groups are long, fast and extensive cross-linking reactions are observed $[70,99,101]$. Cross-linking reactions are deemed responsible for the total or partial insolubility of acrylic coating as a long-term ageing effect. This represents a huge problem when further conservative treatments are required [102].

Due to the above-mentioned stability problems, acrylic resins are nowadays less used as protective coatings for stone, but their physical characteristics and low price still make them a good subject for research. Since the beginning of this century, side-chain fluorination of acrylic or methacrylic-based copolymers has been tested in order to improve the efficiency of acrylic-based copolymers as protective coatings on stone substrates. These recipes aim at enhancing water repellence, increasing the solubility and durability, and maintaining transparency of the coating $[103,104]$. In fact, fluorine in esteric side chain has been demonstrated to be able to increase water repellence and to reduce the water absorbed by capillarity. However, the efficiency of this treatment is principally affected by the surface and bulk characteristics [105].

Different fluoro-acrylic blends have been studied, and a stabilizing effect of fluorination on the polymer properties is generally observed. Benedetti et al. [106] noticed that increasing the percentage of Tecnoflon NM-a fluoroelastomer copolymer based on hexafluoropropene (HFP) and vinylidene fluoride (VDF)—in a blend with Paraloid B72 decreased the degradation through ageing.

New co-polymers based on the fluorinated monomers, as XFDM $(1 \mathrm{H}, 1 \mathrm{H}, 2 \mathrm{H}, 2 \mathrm{H}$-perfluor odecylmethacrylate)/HFIM (1,1,1,3,3,3-hexafluoroisopropylmethacrylate)/EMA(ethyl methacrylate)/ MA(methyl acrylate) and HFIM(1,1,1,3,3,3-hexafluoroisopropylmethacrylate)/EMA(ethylmethacrylate)/ MA (methyl acrylate) have been evaluated and compared with Paraloid B72 and its partially fluorinated homologous TFEM (2,2,2-trifluoroethyl methacrylate)/MA (methyl acrylate) (Table 7). The studies highlighted on one side that long perfluorinated chains are able to lower the surface energy and, consequently, give a higher water contact angle. On the other side, the frequency of occurrence of fluorinated side chains along the macromolecule strongly influence the photo-chemical stability [107]. More recently, a co-polymer, MMA(methyl methacrylate)_POMA(3,3,4,4,5,5,6,6,7,7,8,8,8-tridecafluorooctyl methacrylate), and two ter-polymers, MMA(methyl methacrilate)_nBuMA(N-butyl methacrylate) _POMA (3,3,4,4,5,5,6,6,7,7,8,8,8-tridecafluoro-octyl methacrylate), and EMA(ethyl methacrylate)_nBu MA(N-butylmethacrylate)_POMA(3,3,4,4,5,5,6,6,7,7,8,8,8-tridecafluoro-octyl methacrylate), were 
Table 7. Cont.

\begin{tabular}{ccc}
\hline Polymer & IUPAC name \\
\hline TFEM & 2,2,2-Trifluoroethyl methacrylate \\
POMA & $3,3,4,4,5,5,6,6,7,7,8,8,8$-Tridecafluoro-octyl \\
methacrylate
\end{tabular}

\subsection{Nano-Composites}

Silane and siloxane coatings have been mainly employed on stones as a matrix for nanocomposites. The introduction of the latter is mainly devoted to increase the water repellence of the polymer and has an important role against pollution. In fact, the major relevant properties of those nanocomposites are their superhydrophobic and photocatalytic action, which is extended thanks to the nanometric size of the particles. From one side, the super hydrophobicity guarantees the removal of microorganisms, because they cannot adhere at the coating surface and are washed by rainwater. The second property is instead beneficially used to prevent the accumulation on stone of polluting agents by inducing their decomposition. In fact, photocatalytic composites are capable of absorbing light and lead to the production of oxygen species on their surface, resulting in the blotching of organic chemicals via photo-oxidation [109]. In this way, they can be used as self-cleaning components and against bacteria, preserving the material transparency and flexibility.

The interest on the application of nanocomposites for $\mathrm{CH}$ protective coating is shown in the present literature, which counted hundreds of papers per year in the last decade [110], as well as by the recent Horizon 2020 project, titled "Nano-Cathedral" [111], dedicated to innovative solutions based on nanocomposites for protecting European historical buildings. Because of the large amount of literature on these kinds of materials, we report here some of the results, which allow an in-depth discussion on these applications, whereas additional details can be found in cited references and reviews [112-117].

The primary difficulty of employing nanocomposites in combination with protective polymers is related to the colour alteration induced on the coating film [118]. Despite this material offering a significant protection against biofouling, their use should balance the aesthetic requirement of stone surfaces, as an excessive nanomaterial concentration can lead to an unacceptable colour change. For this reason, it is important to preliminarily work on the optimization of particle rheology, on average particle dimension, density, and refractive index, which have a relevant impact on the photocatalytic efficiency of nanocomposites.

In conservation science, amongst many types of nanocomposites, $\mathrm{TiO}_{2}$ certainly plays a central role, thanks to its elevated photocalyticity (Figure 9). In fact, the self-cleaning action is strictly connected to the photocatalytic properties of the nanocomposite, and the performances of the nanoparticles are usually improved by optimizing the synthesis process. The photocatalytic activity of synthetized nano- $\mathrm{TiO}_{2}$ is usually tested, before the deposition on stone, by means of organic dye decomposition, and the evaluation of the photodegradation is made through colorimetric measurements. In the literature, different types of colourants can be found, and the most diffused are rhodamine B, methyl red and orange, and methylene blue [119]. Despite the elevated number of works, it is difficult to analytically compare these experimental results and determine the characteristics for making optimal nano- $-\mathrm{TiO}_{2}$ because of the significantly different experimental conditions considered, such as dye 
concentration, light exposure, and irradiance, as well as particle size, capping, and crystal structure. A common aspect, however, regards improving efficiency in photocatalysis.

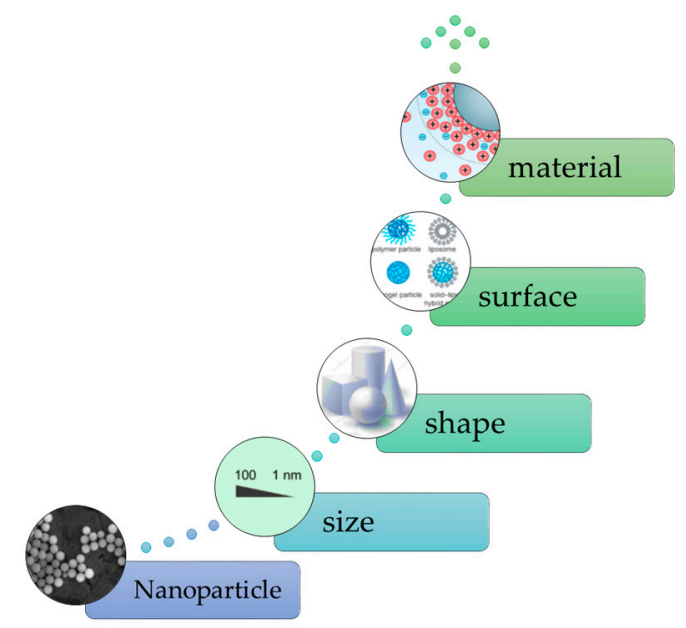

Figure 9. Important properties for engineering nanoparticles (NP) for photo-catalytic performance.

It should be mentioned that the photocatalytic properties of semiconductor materials can be tuned, apart from playing on particle rheology, also by varying their band gap energy. In fact, the energy gap between the valence and conduction bands has a primary influence on the photo-oxidation properties of these materials because of the more-or-less efficient electron-hole pair generation. An easy method to enlarge or reduce the band gap is by doping the semiconductor with other elements compatible with the crystal structure of the semiconductor. This has been done for $\mathrm{TiO}_{2}$ and, amongst other non-metal elements, nitrogen has been demonstrated as the most attractive element for improving the self-cleaning action of titanium oxide because of its comparable atomic size with that of oxygen [120]. It has been shown that nitrogen inclusions reduce the band gap of titania from 3 to $2.5 \mathrm{eV}$, increasing the photocatalytic properties of the oxide without altering the aesthetic properties of carbonate stones, as well as improving the resistance to the capillary water absorption.

Currently, one of the most problematic aspects of employing titania in protective coating for stone is assuring its resistance over time. In fact, it has been shown that the weathering can induce the deactivation of its photocatalytic properties because of the formation of intermediate products, which reduce or block the positive action of $\mathrm{TiO}_{2}$ against fouling accumulation. One proposed solution considers the implementation of three-layered surface treatment, which includes one layer of consolidant, a second hydrophobic layer, and a third self-cleaning layer made of $\mathrm{TiO}_{2}$ nanoparticles [121]. This structure has been demonstrated as being more resistant to UV ageing and ensures a higher water vapour permeability. The success of this and related studies contributes to the "InnovaConcrete" [122], a Horizon 2020 project, which is currently in progress.

As anticipated, crystalline titanium dioxide is the most widely used photocatalyst, but other metal oxide nanoparticles are sometimes preferred $[123,124]$ because they present similar results in terms of self-cleaning and biocidal efficacy. For example, some tests have been done by employing $\mathrm{ZnO}$ as self-cleaning agents, as this oxide has almost the same band gap energy $(3.2 \mathrm{eV})$ and similar photocatalytic properties with respect to titanium oxide, although there is no consensus on which metal oxides has better efficiency [124]. An alternative is represented by zinc titanium oxide, meaning a titanium oxide heavily doped with zinc (i.e., $\mathrm{Zn} / \mathrm{Ti}=0.3$ to 1 ), which shows a better catalyst for oxidation. Ruffolo and collaborators explored the possibility of using $\mathrm{ZnO}$ and $\mathrm{ZnTiO}_{3}$ as an alternative to titanium dioxide, with the aim of obtaining a novel coating technology [123]. The experiments conducted on the effectiveness of $\mathrm{ZnO}$ and $\mathrm{ZnTiO}_{3}$ nanopowders against bacteria showed a higher growth inhibition efficiency of $\mathrm{ZnTiO}_{3}$ than $\mathrm{ZnO}$, whereas the latter induced a remarkable increase of 
contact angle and water capillary absorption after irradiation and therefore was shown by the authors as being less adept for contributing to stone protection.

The second characteristic of nanocomposites appreciated for historical stone protection regards water repellence. The hydrophobicity of stone surface is usually enhanced when $\mathrm{TiO}_{2}$ or other oxides are included in polymeric coating, and it is in fact a parameter normally evaluated when these types of coatings are considered. These are usually referred to as superhydrophobic composites, indicating a specific category of nano-coatings [125]. Prior to the discussion of the most relevant results obtained on these applications, the distinction between hydrophobic and superhydrophobic surfaces are of note [126]. Indeed, this definition is related to the angle formed by a drop of water deposited onto a surface- - if the drop does not tend to spread onto the surface and forms an angle higher than $90^{\circ} \mathrm{C}$ with respect to the horizontal, the surface is called hydrophobic. It follows that for angles greater than $150{ }^{\circ} \mathrm{C}$, the surface can be referred to as superhydrophobic. Amongst various superhydrophobic coatings for stone protection, $\mathrm{SiO}_{2}$ or $\mathrm{SiO}_{2}-\mathrm{TiO}_{2}$ nanoparticles are considered the most effective in this sense [127]. The first superhydrophobic coating for stone materials was developed by Manoudis and co-workers [128] by including $\mathrm{SiO}_{2}$ nanoparticles in a commercial siloxane polymer (Rhodorsil 224), which is commonly used for restoration of stones. A similar approach was employed by inserting $\mathrm{SiO}_{2}$ in TEOS (tetra-ethyl-orthosilicate), which is not waterproof [129], and in an aqueous dispersion containing alkoxy silanes [115]. All these experiments confirm the possibility of providing a superhydrophobic film over the calcareous stone by adding nano-SiO${ }_{2}$, despite the main drawback of using this oxide is once again associated with the colorimetric variation induced on the treated surface.

A recent research investigated the features shown by $\mathrm{SiO}_{2}$ nanoparticles by embedding them in Paraloid B72 [117]. Ntelia and Karapanagiotis proposed this novel nanocoating with the purpose of increase the hydrophobicity of Paraloid B72, applying it on glass, marble, and wood. This formulation based on nanoparticles of $\mathrm{SiO}_{2}$ and the well-known Paraloid B72 showed a good chemical stability and improved the hydrophobicity, although the authors reported that the colour of a treated substrate importantly changes with high nanoparticle concentration. The issue of hydrophobicity is a key topic. In general, water is considered dangerous for stone, but it is not advisable to make the surface totally waterproof [42]. The archaeological and artistic objects always show peculiar shapes, fractures, and roughness that depend also on the aesthetic effects or because of their functions-the surface irregularity can increase the coating hydrophobicity, but concurrently it decreases the transparency. The balance of all these different issues can be hard to find. As final remark, we notice that superhydrophobicity can be in some cases accompanied by superoleophobicity, which is, in a similar way to water, the capability of the film to repel oil and oleic compounds. This can be an important property for monuments against urban air pollution, as discussed in [130], whereas it is reported as belonging also to organically modified silica without the use nanoparticles [116].

Overall, the use of nanocomposites in $\mathrm{CH}$ presents two main criticisms. Ferrari and collaborators critically considered the sustainability of nano-based coatings and pointed out the risks of releasing new engineered nanomaterials into the environment [131]. This is particularly true for those applications on the external face of historical buildings exposed to rain-wash, which therefore can enter the life cycle. It is important that this research put particular attention on the studies conducted on the ecotoxicology of nano-compounds. Easy safety practices should be adopted for ensuring the security for humans and the environment, such as the use of air filter and other protective equipment, of packaging to limit the release of nanoparticle emissions during transport and of specific waste treatment for avoiding any dispersion in soil and water. The second criticism highlighted by recent research regards the efficiency of its application only on optimal substrate conditions. In fact, the research of the last years shows that this depends greatly on the porosity and roughness of the substrate [132] - the higher the values of these two parameters, the lower the beneficial anti-biofouling and self-cleaning effects of nanocomposites $[133,134]$. This issue has been ultimately determined by Quagliarini and co-workers [132], who considered aqueous nano-TiO2 solution sprayed on historical stones characterized by important porosity and roughness. Results demonstrated that, despite the 
nominal photocatalytic power of this oxide, a similar effect is not guaranteed on $\mathrm{CH}$ building materials because their self-cleaning effectiveness is limited by the low amounts of titania required to not alter the aesthetic appearance of the stone. The same authors conclude that the need for further research on the application of different "green" methods and other nano-materials with higher self-cleaning power on non-uniform historical surfaces. It is of note, however, that with respect to other protective coatings, nanocomposites have been, to a large extent, tested on several lithotypes, always demonstrating successful results. Despite this, there is still some reluctance in their application on historical stone and in everyday protective routine. This is probably associated with the short-term experimentation and to the limitative applications of those materials on archaeological sites. It is therefore fundamental to introduce this technology to the $\mathrm{CH}$ community for improving the protection of historical buildings and other archaeological surfaces.

\subsection{Bio-Films}

As discussed at the beginning of this section, the action of microorganisms on stone surfaces can be dangerous from a chemical and mechanical point of view. However, it has been shown that if the presence of microorganisms is controlled, it can help in stone conservation, and this is referred to as bio-protection. Bio-protection is generally associated with the action of microorganisms aimed at reducing the deterioration of stones, acting as protective patina on the surface [135]. The discussion of bio-cleaning is not part of this review, but we mention here the most remarkable results obtained by employing bio-conservation and bio-patinas in order to give the reader an introduction to these important aspects for stone conservation. For a complete overview on this topic, we suggest the recently published work by Fidanza and Caneva [136], who extensively reviewed the natural biocides used for the conservation of stones, proposing additionally a protocol for standardizing the exploration of the bioconservation of the surfaces.

Good experimental results have been obtained with the application of Myxococcus xanthus [137,138], which is a myxobacteria with demonstrated consolidation ability towards carbonate stones. The growing of this heterotrophic bacteria on the surface, in fact, promotes carbonatogenesis-in this case, the formation of the calcite is subsequent to the metabolic activity of the heterotrophic bacteria. $M$. xanthus is capable of activating the calcite precipitation on porous limestone, protecting from carbonate cementation the first 500 microns [137]. Moreover, the precipitation of calcite on calcarenite by means of M. xantus also gives a protection to the surface, acting as a biopatina, suggesting that this methodology can be appropriate in the conservation of historical stones. The aesthetic properties of ornamental stone are also preserved [138].

Not only bacteria have been tested on stone protection, but also vegetation. On buildings, it is common to see outdoor faces covered with plants. When these grow out of control, they can damage the stone, but when the growth is monitored, they can instead contribute to the conservation of the material. For example, an interesting study has been carried out on the role of ivy on building walls [139], on which the contribution of Hedera helix in preserving the historical surfaces was evaluated. In the case of ivy, it has been demonstrated that Hedera helix creates a microclimate that attenuates the thermal cycles, protecting the stone from rain and direct solar radiation. The study did not explore the protection of this plant from air pollution, but the possibility emerged of using this remedy as bioprotection for certain types of buildings naturally exposed to the growth of ivy.

P. Mclloroy de la Rosa et al. [140] deeply reviewed the role of lichens as biopatina for limestones and marbles. The authors examined the action of lichens, concluding that their protection is influenced by many factors, and the safety of the stone is not predictable in the long term. Monitoring must be constant in order to avoid biodegradation. Researchers have demonstrated the capability of lichens in protecting the stones from water, limiting the exchanges between the stone surface and the environment $[95,141]$. On the other hand, research highlights at the same time the damage due to the growth of lichen on stones [142], confirming the need to deeply understand the limit between bioprotection and biodegradation. 
Although cleaning using microorganisms provides good results $[133,143]$, biofilms need to be systematically studied. At present, research is paying more attention on the possibility to turn to the benefits of the presence microorganisms and plants on stone surfaces, and biofilms and biopatinas are more suitable in preserving these materials in the natural environment. This conservative approach should be exploited, especially in the remote and natural environment, where other methods can hardly be applicable.

\section{Conclusions}

The short-time evolution from irreversible, sometimes toxic protectives to more green and eco-friendly coatings shows how the $\mathrm{CH}$ community has become aware of the needs of meeting more sustainable solutions. Nonetheless, novel protective coatings are considered with some diffidence in routine conservative application, whereas the safety of coating application has increased over the years.

As first outcome, the present overview found three main improvements in this field. Starting from 20 years ago, acrylic resins and organic compounds have been importantly used as both consolidant and protective film. These acrylic polymers demonstrate a lack in reversibility, requiring toxic solvents for their removal, and when aged they are often prone to yellowing. As discussed in this work, the most common acrylic resins, such as Incralac, Paraloid B44, and Paraloid B72, showed in large part the ineffectiveness of these compounds on metals, historical glass, and stones. Although these products are sometimes still preferred, in terms of the authors' opinion, they should be abandoned, as many other and more effective coatings are nowadays available and have been successfully tested. Nonetheless, we retain that this initial experimentation has allowed us to understand the importance of finding other recipes and materials, with the safeguard of the material and the aesthetic side as primary aim.

Another step forward made in the last decades has been the translation from the use of products aimed at restoring the cohesion of the material to protective solution. The former, intended as consolidating elements, often penetrates inside the surface, increasing the rigidness of the material itself. Conversely, the protectives have started to be applied to the surface with the sole purpose of protecting it from (external) risk factors, without making a bonding action or filling of delaminated areas. Depositing protective coating on archaeological and artistic materials has been demonstrated as being less invasive than consolidating ones.

Lastly, the third advance regards the need to surpass the use of coatings based on toxic components. For example, BTA has been the most diffused corrosion inhibitor for metals, and it includes almost all the features desired when it is added to a coating: it is transparent; easy to prepare, apply, and remove, resistant to light, and is a corrosion inhibitor. However, BTA, like many other triazole derivatives, is highly toxic and dangerous for both humans and the environment. At present, its use is not accepted anymore. The research shows some difficulties in getting rid of these compounds. From the experimental point of view, the easiest way to reduce its use has been the dilution with other components or with polymers that can limit its toxicity or dispersion in the environment.

Throughout the years, the sensibility towards aspects related to the reversibility and non-toxicity has grown, although the publication of the Theory of Restoration by Cesare Brandi, the basis for all the following regulations in terms of restoration and conservation, dates back to 1963. Starting from the 2010s, the research took a leap forward in the development of protective coatings that were non-toxic, reversible, and adequate to the substrate, and several examples are found in literature. Sometimes these coating solutions represented only a single tentative, stopped at the very beginning of the research, but were considered nonetheless relevant for future studies. The present overview showed evidence of some protective coatings that can be nowadays considered as good protective solutions for archaeological materials, and their application is sustained by extensive research.

Overall, on bronze and more general copper alloys, silane compounds show good effectiveness against corrosion, and the recent trend is to exploit the properties of some nanoparticles as coating themselves or to improve the characteristics of polymeric matrix (i.e., adhesion, transparency, water repellence). On historical glass, hybrid organic-inorganic sol-gel, based on TEOS functionalized with 
alkyl groups, are becoming the best choice. Apart from the appreciated glazy transparency of sol-gel, they have demonstrated good surface water-repellence, an optimal degree of elasticity, as well as stability under UV ageing and corrosion tests. The literature underlines the additional care that has to be taken when dealing with soda-lime and lead silicate glasses, on which the introduction of metal as a catalyst is suggested in order to reduce metal ion exchange on glass surface. Biofilms (microorganisms) and biopolymers (such as poly(lactic acid) and chitosan) have been primarily tested on metals and stones. The best results have been obtained on stones, as the adhesion on this material seems to be easier. The main protective action is against environmental pollution, avoiding the fact that the particles can deposit on the original surface. The advantages of these kind of coatings, both for metals and stones, are their eco-friendly features, easy removal, and low cost. In terms of the authors' opinion and as a final consideration, one of the most interesting scenarios recently established is the application of new coating materials based on nano-technologies. These have not yet reached maturity and the $\mathrm{CH}$ community is not sufficiently informed, but the introduction of nanoparticles in polymeric film can be highly useful to enhance the protective properties of coatings while keeping the required top-qualities. The results obtained are promising, but there are many aspects to be explored and studied for the application of these nano-technologies as a protective coating on $\mathrm{CH}$ materials.

As final remark, we highlight in this conclusion that one of the most important aspects, when introducing protective coatings in conservative application, is the definition of a protocol. This should include the following steps (Figure 10): (i) evaluation of the surface deterioration and definition of the conservation status of the object. This preliminary step is fundamental for the application of a proper protective coating, as every artistic and archaeological specimen is a unique piece with a unique history. (ii) Creation of artificial specimens that reproduce corroded or degraded layers, as found on ancient objects. (iii) Tests of new coating products on standard objects and following (iv) corrosion and ageing experiments on standard samples on which the corroded or degraded layer is reproduced artificially. (v) Validation of coating durability and removability for finally determine under which condition its application can be retain safe for the object. If one of these steps gives bad results or is not sufficiently effective, the protocol should consider again the first steps in order to optimize the procedure. On the other side, in case every test was surpassed without any doubt, the application can be performed on ancient objects. This last experiment can be found in the literature in only a few examples. This choice evidently lies in the uniqueness of the object itself, but it can sometimes limit the possibility to foresee possible damages or changes of the coating induced by a long-natural progression of time. Illustrative results presented in this work give evidence to the complexity of archaeological artefacts, which often are fragile, suffer from superficial corrosion, and on which industrial protective methods can result as being inadequate. Defining a protocol could help in correctly evaluating the possibility of safely applying new protective coatings on archaeological and ancient specimens.

At this stage, reversibility and re-treatments are considered necessary research to be conducted for making these new protective coatings a secure application for $\mathrm{CH}$ materials. The attention must be put on the application of eco-friendly coating and easy and low-cost synthesis processes, which are nowadays amongst the top properties required in any technological field. 


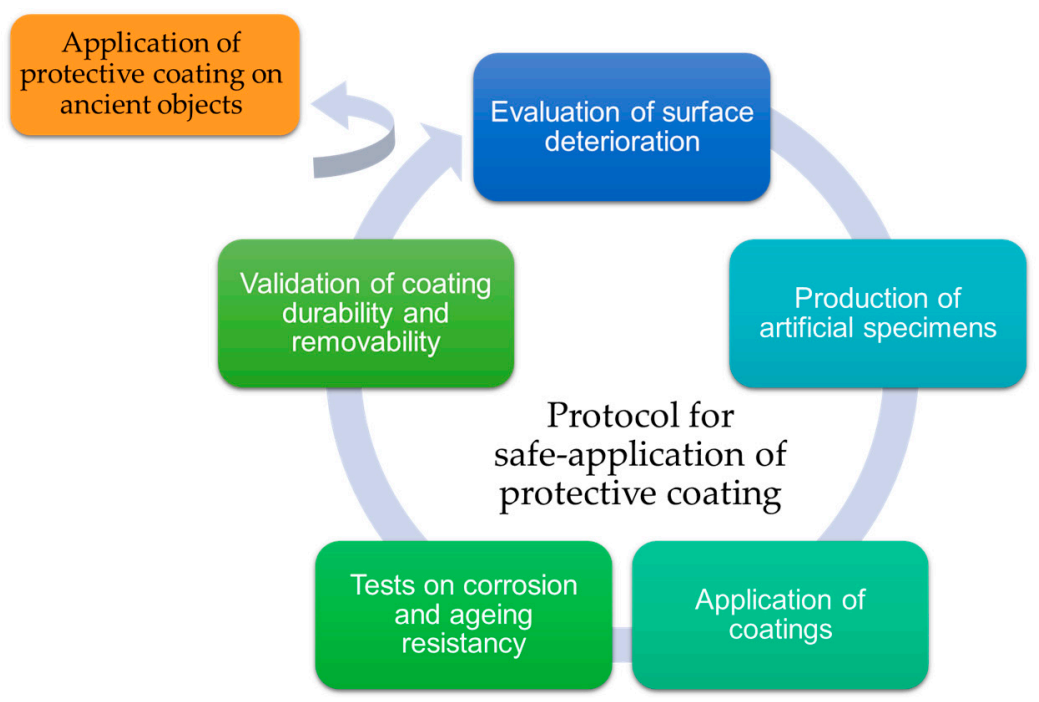

Figure 10. Protocol to design a safe application of new protective coating.

Author Contributions: Writing-original draft preparation, A.A., F.D.T., M.Z.; writing-review and editing, A.A., F.D.T., A.T.; supervision, A.T. All authors have read and agreed to the published version of the manuscript.

Funding: This research received no external funding.

Acknowledgments: Not applicable.

Conflicts of Interest: The authors declare no conflict of interest.

\section{References}

1. Brandi, C. Il Restauro. Teoria e Pratica (1939-1986); Saggi Arte; Editori Riuniti: Roma, Italy, 2009.

2. Godoi, R.H.M.; Kontozova, V.; van Grieken, R. The shielding effect of the protective glazing of historical stained glass windows from an atmospheric chemistry perspective: Case study Sainte Chapelle, Paris. Atmos. Environ. 2006. [CrossRef]

3. De Ferri, L.; Lottici, P.P.; Lorenzi, A.; Montenero, A.; Vezzalini, G. Hybrid sol-gel based coatings for the protection of historical window glass. J. Sol-Gel Sci. Technol. 2013, 66, 253-263. [CrossRef]

4. Davison, S. A review of adhesives and consolidants used on glass antiquities. Stud. Conserv. 2014. [CrossRef]

5. Revie, R.W. An Introduction to Corrosion Science and Engineering, 4th ed.; John Wiley \& Sons: Hoboken, NJ, USA, 2008. [CrossRef]

6. Ivaskova, M.; Kotes, P.; Brodnan, M. Air pollution as an important factor in construction materials deterioration in Slovak Republic. Procedia Eng. 2015, 108, 131-138. [CrossRef]

7. Di Turo, F.; Proietti, C.; Screpanti, A.; Fornasier, M.F.; Cionni, I.; Favero, G.; De Marco, A. Impacts of air pollution on cultural heritage corrosion at European level: What has been achieved and what are the future scenarios. Environ. Pollut. 2016, 218, 1-9. [CrossRef]

8. Bernardi, E.; Chiavari, C.; Lenza, B.; Martini, C.; Morselli, L.; Ospitali, F.; Robbiola, L. The atmospheric corrosion of quaternary bronzes: The leaching action of acid rain. Corros. Sci. 2009, 51, 159-170. [CrossRef]

9. Robbiola, L.; Blengino, J.M.; Fiaud, C. Morphology and mechanisms of formation of natural patinas on archaeological Cu-Sn alloys. Corros. Sci. 1998, 40, 2083-2111. [CrossRef]

10. Fabrizi, L.; Di Turo, F.; Medeghini, L.; Di Fazio, M.; Catalli, F.; De Vito, C. The application of non-destructive techniques for the study of corrosion patinas of ten Roman silver coins: The case of the medieval Grosso Romanino. Microchem. J. 2019, 145, 419-427. [CrossRef]

11. Doménech-Carbò, A.; Doménech-Carbó, M.T.; Pasies, T.; Bouzas, M.d. Modeling Corrosion of Archaeological Silver-Copper Coins Using the Voltammetry of Immobilized Particles. Electroanalysis 2012, 24, 1945-1955. [CrossRef]

12. Di Fazio, M.; Felici, A.C.; Catalli, F.; De Vito, C. Microstructure and chemical composition of Roman orichalcum coins emitted after the monetary reform of Augustus (23 B.C.). Sci. Rep. 2019, 9, 1-11. [CrossRef] 
13. Papadopoulou, O.; Vassiliou, P.; Grassini, S.; Angelini, E.; Gouda, V. Soil-induced corrosion of ancient Roman brass-A case study. Mater. Corros. 2016, 67, 160-169. [CrossRef]

14. Zhou, P.; Hutchison, M.J.; Erning, J.W.; Scully, J.R.; Ogle, K. An in situ kinetic study of brass dezincification and corrosion. Electrochim. Acta 2017, 229, 141-154. [CrossRef]

15. Qiu, P.; Leygraf, C. Initial oxidation of brass induced by humidified air. Appl. Surf. Sci. 2011, 258, $1235-1241$. [CrossRef] [PubMed]

16. Barr, T.L.; Hackenberg, J.J. Determination of the onset of the dezincification of .alpha.-brass using x-ray photoelectron (ESCA) spectroscopy. J. Am. Chem. Soc. 1982, 104, 5390-5394. [CrossRef]

17. Refait, P.; Abdelmoula, M.; Génin, J.M.R. Mechanisms of formation and structure of green rust one in aqueous corrosion of iron in the presence of chloride ions. Corros. Sci. 1998, 40, 1547-1560. [CrossRef]

18. Dillmann, P.; Mazaudier, F.; Hœrlé, S. Advances in understanding atmospheric corrosion of iron. I. Rust characterisation of ancient ferrous artefacts exposed to indoor atmospheric corrosion. Corros. Sci. 2004, 46, 1401-1429. [CrossRef]

19. Doménech, A.; Lastras, M.; Rodríguez, F.; Osete, L. Mapping of corrosion products of highly altered archeological iron using voltammetry of microparticles. Microchem. J. 2013, 106, 41-50. [CrossRef]

20. Neff, D.; Dillmann, P.; Bellot-Gurlet, L.; Beranger, G. Corrosion of iron archaeological artefacts in soil: Characterisation of the corrosion system. Corros. Sci. 2005, 47, 515-535. [CrossRef]

21. Ashkenazi, D.; Nusbaum, I.; Shacham-Diamand, Y.; Cvikel, D.; Kahanov, Y.; Inberg, A. A method of conserving ancient iron artefacts retrieved from shipwrecks using a combination of silane self-assembled monolayers and wax coating. Corros. Sci. 2017, 123, 88-102. [CrossRef]

22. Johnson, R. The removal of microcrystalline wax from archaeological ironwork. Stud. Conserv. 1984, 29, 107-109. [CrossRef]

23. Favre-quattropani, L.; Groening, P.; Ramseyer, D.; Schlapbach, L. The protection of metallic archaeological objects using plasma polymer coatings. Surf. Coat. Technol. 2000, 125, 377-382. [CrossRef]

24. Klages, C.P.; Dietz, A.; Höing, T.; Thyen, R.; Weber, A.; Willich, P. Deposition and properties of carbon-based amorphous protective coatings. Surf. Coat. Technol. 1996, 80, 121-128. [CrossRef]

25. Kosec, T.; Kek, D.; Milošev, I. Impedance and XPS study of benzotriazole films formed on copper, copper-zinc alloys and zinc in chloride solution. Corros. Sci. 2008, 50, 1987-1997. [CrossRef]

26. Bierwagen, G.; Shedlosky, T.J.; Stanek, K. Developing and testing a new generation of protective coatings for outdoor bronze sculpture. Prog. Org. Coat. 2003, 48, 289-296. [CrossRef]

27. Kosec, T.; Legat, A.; Miloev, I. The comparison of organic protective layers on bronze and copper. Prog. Org. Coat. 2010, 69, 199-206. [CrossRef]

28. Rahmouni, K.; Takenouti, H.; Hajjaji, N.; Srhiri, A.; Robbiola, L. Protection of ancient and historic bronzes by triazole derivatives. Electrochim. Acta 2009, 54, 5206-5215. [CrossRef]

29. Finšgar, M.; Milošev, I. Inhibition of copper corrosion by 1,2,3-benzotriazole: A review. Corros. Sci. 2010, 52, 2737-2749. [CrossRef]

30. Faltermeier, R.B. A corrosion inhibitor test for copper-based artifacts. Stud. Conserv. 1999, 44, $121-128$. [CrossRef]

31. Brunoro, G.; Frignani, A.; Colledan, A.; Chiavari, C. Organic films for protection of copper and bronze against acid rain corrosion. Corros. Sci. 2003, 45, 2219-2231. [CrossRef]

32. Galtayries, A.; Mongiatti, A.; Marcus, P.; Chiavari, C. Surface characterisation of corrosion inhibitors on bronzes for artistic casting. In Corrosion of Metallic Heritage Artefacts; Woodhead Publishing: Sawston, UK, 2007; pp. 335-351. [CrossRef]

33. Balbo, A.; Chiavari, C.; Martini, C.; Monticelli, C. Effectiveness of corrosion inhibitor films for the conservation of bronzes and gilded bronzes. Corros. Sci. 2012, 59, 204-212. [CrossRef]

34. Ulman, A. Formation and Structure of Self-Assembled Monolayers. Chem. Rev. 1996, 96, 1533-1554. [CrossRef] [PubMed]

35. Schreiber, F. Structure and growth of self-assembling monolayers. Prog. Surf. Sci. 2000, 65, 151-257. [CrossRef]

36. Varvara, S.; Muresan, L.M.; Rahmouni, K.; Takenouti, H. Evaluation of some non-toxic thiadiazole derivatives as bronze corrosion inhibitors in aqueous solution. Corros. Sci. 2008, 50, 2596-2604. [CrossRef] 
37. Muresan, L.; Varvara, S.; Stupnišek-Lisac, E.; Otmačić, H.; Marušić, K.; Horvat-Kurbegović, S.; Takenouti, H. Protection of bronze covered with patina by innoxious organic substances. Electrochim. Acta 2007, 52, 7770-7779. [CrossRef]

38. Muresan, L.; Oniciu, L.; Froment, M.; Maurin, G. Inhibition of lead electrocrystallization by organic additives. Electrochim. Acta 1992, 37, 2249-2254. [CrossRef]

39. Chiavari, C.; Balbo, A.; Bernardi, E.; Martini, C.; Bignozzi, M.C.; Abbottoni, M.; Monticelli, C. Protective silane treatment for patinated bronze exposed to simulated natural environments. Mater. Chem. Phys. 2013, 141, 502-511. [CrossRef]

40. Masi, G.; Josse, C.; Esvan, J.; Chiavari, C.; Bernardi, E.; Martini, C.; Fabjan, E.S. Evaluation of the protectiveness of an organosilane coating on patinated Cu-Si-Mn bronze for contemporary art. Prog. Org. Coat. 2019, 127, 286-299. [CrossRef]

41. Aufray, M.; Josse, C.; Balbo, A.; Monticelli, C.; Fabjan, E.Š.; Škrlep, L.; Chiavari, C. Practical adhesion measurements of protective coatings on bronze by three-point bending test. J. Coat. Technol. Res. 2019, 16, 1465-1477. [CrossRef]

42. Sadat-Shojai, M.; Ershad-Langroudi, A. Polymeric coatings for protection of historic monuments: Opportunities and challenges. J. Appl. Polym. Sci. 2009, 112, 2535-2551. [CrossRef]

43. Kosec, T.; Škrlep, L.; Fabjan, E.Š.; Škapin, A.S.; Masi, G.; Bernardi, E.; Robbiola, L. Development of multi-component fluoropolymer based coating on simulated outdoor patina on quaternary bronze. Prog. Org. Coat. 2019, 131, 27-35. [CrossRef]

44. Lettieri, M.; Masieri, M.; Pipoli, M.; Morelli, A.; Frigione, M. Anti-Graffiti Behavior of Oleo/Hydrophobic Nano-Filled Coatings Applied on Natural Stone Materials. Coatings 2019, 9, 740. [CrossRef]

45. Frigione, M.; Lettieri, M. Novel Attribute of Organic-Inorganic Hybrid Coatings for Protection and Preservation of Materials (Stone and Wood) Belonging to Cultural Heritage. Coatings 2018, 8, 319. [CrossRef]

46. Bescher, E.; Mackenzie, J.D. Sol-gel coatings for the protection of brass and bronze. J. Sol. Gel. Sci. Technol. 2003, 26, 1223-1226. [CrossRef]

47. Meng, B.; Mueller, U.; Garcia, O.; Malaga, K. Performance of a New Anti-Graffiti Agent Used for Immovable Cultural Heritage Objects. Int. J. Archit. Herit. 2014, 8, 820-834. [CrossRef]

48. Ling, H.; Maiqian, N.; Guozheng, L. Preparation and feasibility analysis of fluoropolymer to the sandstone protection. Prog. Org. Coat. 2008, 62, 206-213. [CrossRef]

49. Faraldi, F.; Cortese, B.; Caschera, D.; Di Carlo, G.; Riccucci, C.; De Caro, T.; Ingo, G.M. Smart conservation methodology for the preservation of copper-based objects against the hazardous corrosion. Thin Solid Film. 2017, 622, 130-135. [CrossRef]

50. Salzano de Luna, M.; Buonocore, G.G.; Giuliani, C.; Messina, E.; Di Carlo, G.; Lavorgna, M.; Ingo, G.M. Long-Lasting Efficacy of Coatings for Bronze Artwork Conservation: The Key Role of Layered Double Hydroxide Nanocarriers in Protecting Corrosion Inhibitors from Photodegradation. Angew. Chem. Int. Ed. 2018, 57, 7380-7384. [CrossRef]

51. Kiele, E.; Lukseniene, J.; Griguceviciene, A.; Selskis, A.; Senvaitiene, J.; Ramanauskas, R.; Kareiva, A. Methyl-modified hybrid organic-inorganic coatings for the conservation of copper. J. Cult. Herit. 2014, 15, 242-249. [CrossRef]

52. El-Haddad, M.N. Chitosan as a green inhibitor for copper corrosion in acidic medium. Int. J. Biol. Macromol. 2013, 55, 142-149. [CrossRef]

53. Wang, T.; Wang, J.; Wu, Y. The inhibition effect and mechanism of 1-cysteine on the corrosion of bronze covered with a CuCl patina. Corros. Sci. 2015, 97, 89-99. [CrossRef]

54. Badawy, W.A.; Ismail, K.M.; Medany, S.S. Optimization of the electropolymerization of 1-amino-9,10-anthraquinone conducting films from aqueous media. Electrochim. Acta 2006, 51, 6353-6360. [CrossRef]

55. Ismail, K.M. Evaluation of cysteine as environmentally friendly corrosion inhibitor for copper in neutral and acidic chloride solutions. Electrochim. Acta 2007, 52, 7811-7819. [CrossRef]

56. Albini, M.; Letardi, P.; Mathys, L.; Brambilla, L.; Schröter, J.; Junier, P.; Joseph, E. Comparison of a bio-based corrosion inhibitor versus benzotriazole on corroded copper surfaces. Corros. Sci. 2018, 143, 84-92. [CrossRef]

57. Giuntoli, G.; Rosi, L.; Frediani, M.; Sacchi, B.; Salvadori, B.; Porcinai, S.; Frediani, P. Novel coatings from renewable resources for the protection of bronzes. Prog. Org. Coat. 2014, 77, 892-903. [CrossRef] 
58. Pedna, A.; Giuntoli, G.; Frediani, M.; Frediani, P.; Rosi, L. Synthesis of functionalized polyolefins with novel applications as protective coatings for stone Cultural Heritage. Prog. Org. Coat. 2013, 76, 1600-1607. [CrossRef]

59. Giuliani, C.; Pascucci, M.; Riccucci, C.; Messina, E.; de Luna, M.S.; Lavorgna, M.; Di Carlo, G. Chitosan-based coatings for corrosion protection of copper-based alloys: A promising more sustainable approach for cultural heritage applications. Prog. Org. Coat. 2018, 122, 138-146. [CrossRef]

60. Grassini, S.; Angelini, E.; Mao, Y.; Novakovic, J.; Vassiliou, P. Aesthetic coatings for silver based alloys with improved protection efficiency. Prog. Org. Coat. 2011, 72, 131-137. [CrossRef]

61. Milanesi, C.; Baldi, F.; Borin, S.; Brusetti, L.; Ciampolini, F.; Iacopini, F.; Cresti, M. Deterioration of medieval painting in the chapel of the Holy Nail, Siena (Italy) partially treated with Paraloid B72. Int. Biodeterior. Biodegrad. 2009, 63, 844-850. [CrossRef]

62. Scalarone, D.; Lazzari, M.; Chiantore, O. Acrylic protective coatings modified with titanium dioxide nanoparticles: Comparative study of stability under irradiation. Polym. Degrad. Stab. 2012. [CrossRef]

63. Cano, E.; Bastidas, D.M.; Argyropoulos, V.; Fajardo, S.; Siatou, A.; Bastidas, J.M.; Degrigny, C. Electrochemical characterization of organic coatings for protection of historic steel artefacts. J. Solid State Electrochem. 2010, 14, 453-463. [CrossRef]

64. Barrera, P.R.; Gómez, F.R.; Ochoa, E.G. Assessing of New Coatings for Iron Artifacts Conservation by Recurrence Plots Analysis. Coatings 2018, 9, 12. [CrossRef]

65. de Bardi, M.; Hutter, H.; Schreiner, M.; Bertoncello, R. Sol-gel silica coating for potash-lime-silica stained glass: Applicability and protective effect. J. Non. Cryst. Solids 2014. [CrossRef]

66. Melcher, M.; Wiesinger, R.; Schreiner, M. Degradation of glass artifacts: Application of modern surface analytical techniques. Acc. Chem. Res. 2010. [CrossRef] [PubMed]

67. de Bardi, M.; Hutter, H.; Schreiner, M.; Bertoncello, R. Potash-lime-silica glass: Protection from weathering. Herit. Sci. 2015. [CrossRef]

68. Bernardi, A.; Becherini, F.; Bassato, G.; Bellio, M. Condensation on ancient stained glass windows and efficiency of protective glazing systems: Two French case studies, Sainte-Chapelle (Paris) and Saint-Urbain Basilica (Troyes). J. Cult. Herit. 2006. [CrossRef]

69. Klein, L.; Aparicio, M.; Jitianu, A. Handbook of Sol-Gel Science and Technology; Springer: Berlin/Heidelberg, Germany, 2018. [CrossRef]

70. Lazzari, M.; Chiantore, O. Drying and oxidative degradation of linseed oil. Polym. Degrad. Stab. 1999, 65, 303-313. [CrossRef]

71. Abd-Allah, R. Stabilization and treatment of corroded glass objects displayed in the museum of Jordanian heritage. Mediterr. Archaeol. Archaeom. 2007, 7, 19-28.

72. Abd-Allah, R. In situ glass conservation: A case study from the archaeological site of Barsinia, Jordan. Adumatu J. 2007, 16, 25-36.

73. Bougault, V. La Restauration des Vitraux Anciens; Laboratoire de Recherche des Monuments Historiques: Champs-sur-Marne, France, 2004.

74. Wheeler, G. Sol-gel science and cultural heritage. In Handbook of Sol-Gel Science and Technology; Springer: Berlin/Heidelberg, Germany, 2018. [CrossRef]

75. Carmona, N.; Villegas, M.A.; Navarro, J.M.F. Protective silica thin coatings for historical glasses. Thin Solid Film. 2004. [CrossRef]

76. Monti, M.; Bianco, B.D.; Bertoncello, R.; Voltolina, S. New protective coatings for ancient glass: Silica thin-films from perhydropolysilazane. J. Cult. Herit. 2008. [CrossRef]

77. Bertoncello, R.; Monti, M.; Sada, C. Silica thin-films from perhydropolysilazane for the protection of ancient glass. Mater. Sci. 2016, 106-113. [CrossRef]

78. Bertoncello, R.; Milanese, L.; Dran, J.C.; Bouquillon, A.; Sada, C. Sol-gel deposition of silica films on silicate glasses: Influence of the presence of lead in the glass or in precursor solutions. J. Non. Cryst. Solids 2006. [CrossRef]

79. Bianco, B.D.; Bertoncello, R. Sol-gel silica coatings for the protection of cultural heritage glass. Nucl. Instrum. Methods Phys. Res. Sect. B Beam Interact. Mater. Atoms. 2008. [CrossRef]

80. Carmona, N.; Villegas, M.A.; Navarro, J.M.F. Sol-gel coatings in the $\mathrm{ZrO}_{2}-\mathrm{SiO}_{2}$ system for protection of historical works of glass. Thin Solid Film. 2006. [CrossRef] 
81. Holubová, B.; Cílová, Z.Z.; Kučerová, I.; Zlámal, M. Weatherability of hybrid organic-inorganic silica protective coatings on glass. Prog. Org. Coat. 2015. [CrossRef]

82. Tsakalof, A.; Manoudis, P.; Karapanagiotis, I.; Chryssoulakis, I.; Panayiotou, C. Assessment of synthetic polymeric coatings for the protection and preservation of stone monuments. J. Cult. Herit. 2007, 8, 69-72. [CrossRef]

83. Brimblecombe, P.; Grossi, C.M. Millennium-long damage to building materials in London. Sci. Total Environ. 2009, 407, 1354-1361. [CrossRef]

84. Ghedini, N.; Ozga, I.; Bonazza, A.; Dilillo, M.; Cachier, H.; Sabbioni, C. Atmospheric aerosol monitoring as a strategy for the preventive conservation of urban monumental heritage: The Florence Baptistery. Atmos. Environ. 2011, 45, 5979-5987. [CrossRef]

85. Belfiore, C.M.; Barca, D.; Bonazza, A.; Comite, V.; La Russa, M.F.; Pezzino, A.; Sabbioni, C. Application of spectrometric analysis to the identification of pollution sources causing cultural heritage damage. Environ. Sci. Pollut. Res. 2013, 20, 8848-8859. [CrossRef]

86. Grossi, C.M.; Murray, M. Characteristics of carbonate building stones that influence the dry deposition of acidic gases. Constr. Build. Mater. 1999, 13, 101-108. [CrossRef]

87. Mosca, S.; Artesani, A.; Gulotta, D.; Nevin, A.; Goidanich, S.; Valentini, G.; Comelli, D. Raman mapping and time-resolved photoluminescence imaging for the analysis of a cross-section from a modern gypsum sculpture. Microchem. J. 2018, 139, 500-505. [CrossRef]

88. Orecchio, S. Analytical method, pattern and sources of polycyclic aromatic hydrocarbons (PAHs) in the stone of the Temples of Agrigento (Italy). J. Hazard. Mater. 2010, 176, 339-347. [CrossRef] [PubMed]

89. Searle, D.E.; Mitchell, D.J. The effect of coal and diesel particulates on the weathering loss of Portland Limestone in an urban environment. Sci. Total Environ. 2006, 370, 207-223. [CrossRef] [PubMed]

90. Massey, S.W. The effects of ozone and $\mathrm{NO}(\mathrm{x})$ on the deterioration of calcareous stone. Sci. Total Environ. 1999, 227, 109-121. [CrossRef]

91. Cultrone, G.; Sebastián, E. Laboratory simulation showing the influence of salt efflorescence on the weathering of composite building materials. Environ. Geol. 2008, 56, 729-740. [CrossRef]

92. Nuhoglu, Y.; Oguz, E.; Uslu, H.; Ozbek, A.; Ipekoglu, B.; Ocak, I.; Hasenekoglu, I. The accelerating effects of the microorganisms on biodeterioration of stone monuments under air pollution and continental-cold climatic conditions in Erzurum, Turkey. Sci. Total Environ. 2006, 364, 272-283. [CrossRef]

93. Warscheid, T.; Braams, J. Biodeterioration of stone: A review. Int. Biodeterior. Biodegrad. 2000, 46, 343-368. [CrossRef]

94. Zanardini, E.; Abbruscato, P.; Ghedini, N.; Realini, M.; Sorlini, C. Influence of atmospheric pollutants on the biodeterioration of stone. Int. Biodeterior. Biodegrad. 2000, 45, 35-42. [CrossRef]

95. Garcia-Vallés, M.; Topal, T.; Vendrell-Saz, M. Lichenic growth as a factor in the physical deterioration or protection of Cappadocian monuments. Environ. Geol. 2003, 43, 776-781. [CrossRef]

96. Herrera, L.K.; Arroyave, C.; Guiamet, P.; de Saravia, S.G.; Videla, H. Biodeterioration of peridotite and other constructional materials in a building of the Colombian cultural heritage. Int. Biodeterior. Biodegrad. 2004, 135-141. [CrossRef]

97. Diakumaku, E.; Gorbushina, A.A.; Krumbein, W.E.; Panina, L.; Soukharjevski, S. Black fungi in marble and limestones-An aesthetical, chemical and physical problem for the conservation of monuments. Sci. Total Environ. 1995, 167, 295-304. [CrossRef]

98. Feller, R.L. New solvent-type varnishes. Stud. Conserv. 1961. [CrossRef]

99. Melo, M.J.; Bracci, S.; Camaiti, M.; Chiantore, O.; Piacenti, F. Photodegradation of acrylic resins used in the conservation of stone. Polym. Degrad. Stab. 1999. [CrossRef]

100. Favaro, M.; Mendichi, R.; Ossola, F.; Russo, U.; Simon, S.; Tomasin, P.; Vigato, P.A. Evaluation of polymers for conservation treatments of outdoor exposed stone monuments. Part I: Photo-oxidative weathering. Polym. Degrad. Stab. 2006. [CrossRef]

101. Chiantore, O.; Lazzari, M. Photo-oxidative stability of paraloid acrylic protective polymers. Polymer 2001. [CrossRef]

102. Baer, N.S.; Feller, R.L. Accelerated Aging: Photochemical and Thermal Aspects. J. Am. Inst. Conserv. 1996. [CrossRef] 
103. Alessandrini, G.; Aglietto, M.; Castelvetro, V.; Ciardelli, F.; Peruzzi, R.; Toniolo, L. Comparative evaluation of fluorinated and unfluorinated acrylic copolymers as water-repellent coating materials for stone. J. Appl. Polym. Sci. 2000. [CrossRef]

104. Sabatini, V.; Cattò, C.; Cappelletti, G.; Cappitelli, F.; Antenucci, S.; Farina, H.; Di Silvestro, G. Protective features, durability and biodegration study of acrylic and methacrylic fluorinated polymer coatings for marble protection. Prog. Org. Coat. 2018. [CrossRef]

105. Poli, T.; Toniolo, L. Protection efficacy of fluorinated acrylic copolymers applied on historical Italian marbles. Mater. Res. Soc. Symp. Proc. 2005. [CrossRef]

106. Benedetti, E.; D'Alessio, A.; Zini, M.F.; Bramanti, E.; Tirelli, N.; Vergamini, P.; Moggi, G. Characterization of acrylic resins and fluoroelastomer blends as potential materials in stone protection. Polym. Int. 2000. [CrossRef]

107. Toniolo, L.; della Volpe, C.; Brugnara, M.; Poli, T. Partially fluorinated acrylic copolymers as coatings for stone protection: Characterization and surface properties. Mater. Res. Soc. Symp. Proc. 2002. [CrossRef]

108. Jensen, A.A.; Poulsen, P.B.; Bossi, R.; Miljøundersøgelser, D.; FORCE Technology. Survey and Environmental/Health Assessment of Fluorinated Substances in Impregnated Consumer Products and Impregnating Agents; Danish Environmental Protection Agency: Copenhagen, Denmark, 2008.

109. Wang, R.; Hashimoto, K.; Fujishima, A.; Chikuni, M.; Kojima, E.; Kitamura, A.; Watanabe, T. Photogeneration of highly amphiphilic $\mathrm{TiO}_{2}$ surfaces. Adv. Mater. 1998. [CrossRef]

110. Munafò, P.; Goffredo, G.B.; Quagliarini, E. $\mathrm{TiO}_{2}$-based nanocoatings for preserving architectural stone surfaces: An overview. Constr. Build. Mater. 2015. [CrossRef]

111. Nano-Cathedral. Available online: http://www.nanocathedral.eu (accessed on 21 January 2020).

112. Boostani, H.; Modirrousta, S. Review of Nanocoatings for Building Application. Procedia Eng. 2016, 145, 1541-1548. [CrossRef]

113. Das, S.; Kumar, S.; Samal, S.K.; Mohanty, S.; Nayak, S.K. A Review on Superhydrophobic Polymer Nanocoatings: Recent Development and Applications. Ind. Eng. Chem. Res. 2018, 57, 2727-2745. [CrossRef]

114. Aldoasri, M.; Darwish, S.; Adam, M.; Elmarzugi, N.; Ahmed, S. Protecting of Marble Stone Facades of Historic Buildings Using Multifunctional $\mathrm{TiO}_{2}$ Nanocoatings. Sustainability 2017, 9, 2002. [CrossRef]

115. Aslanidou, D.; Karapanagiotis, I.; Lampakis, D. Waterborne superhydrophobic and superoleophobic coatings for the protection of marble and sandstone. Materials 2018, 11, 585. [CrossRef]

116. Karapanagiotis, I.; Pavlou, A.; Manoudis, P.N.; Aifantis, K.E. Water repellent ORMOSIL films for the protection of stone and other materials. Mater. Lett. 2014, 131, 276-279. [CrossRef]

117. Ntelia, E.; Karapanagiotis, I. Superhydrophobic Paraloid B72. Prog. Org. Coat. 2020, 139. [CrossRef]

118. Miliani, C.; Velo-Simpson, M.L.; Scherer, G.W. Particle-modified consolidants: A study on the effect of particles on sol-gel properties and consolidation effectiveness. J. Cult. Herit. 2007. [CrossRef]

119. Gherardi, F.; Colombo, A.; Goidanich, S.; Simonutti, R.; Toniolo, L. Innovative Nano-TiO 2 Particles for Self-cleaning Treatments of Historic Architecture and Sculptures. Restor. Build. Mouments 2014. [CrossRef]

120. Bergamonti, L.; Predieri, G.; Paz, Y.; Fornasini, L.; Lottici, P.P.; Bondioli, F. Enhanced self-cleaning properties of $\mathrm{N}$-doped $\mathrm{TiO}_{2}$ coating for Cultural Heritage. Microchem. J. 2017. [CrossRef]

121. Kapridaki, C.; Verganelaki, A.; Dimitriadou, P.; Maravelaki-Kalaitzaki, P. Conservation of monuments by a three-layered compatible treatment of TEOS-Nano-Calcium Oxalate consolidant and TEOS-PDMS-TiO 2 hydrophobic/photoactive hybrid nanomaterials. Materials 2018, 11, 684. [CrossRef]

122. Innovaconcrete. Available online: http://www.innovaconcrete.eu (accessed on 21 January 2020).

123. Ruffolo, S.A.; la Russa, M.F.; Malagodi, M.; Rossi, C.O.; Palermo, A.M.; Crisci, G.M. ZnO and ZnTiO 3 nanopowders for antimicrobial stone coating. Appl. Phys. A Mater. Sci. Process. 2010. [CrossRef]

124. Aldosari, M.A.; Darwish, S.S.; Adam, M.A.; Elmarzugi, N.A.; Ahmed, S.M. Using ZnO nanoparticles in fungal inhibition and self-protection of exposed marble columns in historic sites. Archaeol. Anthropol. Sci. 2019. [CrossRef]

125. Ruffolo, S.A.; la Russa, M.F. Nanostructured coatings for stone protection: An overview. Front. Mater. 2019. [CrossRef]

126. Feng, L.; Zhang, Y.; Xi, J.; Zhu, Y.; Wang, N.; Xia, F.; Jiang, L. Petal effect: A superhydrophobic state with high adhesive force. Langmuir 2008, 24, 4114-4119. [CrossRef] [PubMed]

127. Pinho, L.; Elhaddad, F.; Facio, D.S.; Mosquera, M.J. A novel $\mathrm{TiO}_{2}-\mathrm{SiO}_{2}$ nanocomposite converts a very friable stone into a self-cleaning building material. Appl. Surf. Sci. 2013. [CrossRef] 
128. Manoudis, P.N.; Karapanagiotis, I.; Tsakalof, A.; Zuburtikudis, I.; Kolinkeová, B.; Panayiotou, C. Superhydrophobic films for the protection of outdoor cultural heritage assets. Appl. Phys. A Mater. Sci. Process. 2009. [CrossRef]

129. de Ferri, L.; Lottici, P.P.; Lorenzi, A.; Montenero, A.; Salvioli-Mariani, E. Study of silica nanoparticles-polysiloxane hydrophobic treatments for stone-based monument protection. J. Cult. Herit. 2011. [CrossRef]

130. Aslanidou, D.; Karapanagiotis, I.; Panayiotou, C. Tuning the wetting properties of siloxane-nanoparticle coatings to induce superhydrophobicity and superoleophobicity for stone protection. Mater. Des. 2016, 108, 736-744. [CrossRef]

131. Ferrari, A.M.; Pini, M.; Neri, P.; Bondioli, F. Nano-TiO ${ }_{2}$ Coatings for Limestone: Which Sustainability for Cultural Heritage? Coatings 2015, 5, 232-245. [CrossRef]

132. Quagliarini, E.; Graziani, L.; Diso, D.; Licciulli, A.; D'Orazio, M. Is nano- $\mathrm{TiO}_{2}$ alone an effective strategy for the maintenance of stones in Cultural Heritage? J. Cult. Herit. 2018. [CrossRef]

133. Goffredo, G.B.; Accoroni, S.; Totti, C.; Romagnoli, T.; Valentini, L.; Munafò, P. Titanium dioxide based nanotreatments to inhibit microalgal fouling on building stone surfaces. Build. Environ. 2017. [CrossRef]

134. Graziani, L.; Quagliarini, E.; Osimani, A.; Aquilanti, L.; Clementi, F.; D'Orazio, M. The influence of clay brick substratum on the inhibitory efficiency of $\mathrm{TiO}_{2}$ nanocoating against biofouling. Build. Environ. 2014. [CrossRef]

135. Carter, N.E.A.; Viles, H.A. Bioprotection explored: The story of a little known earth surface process. Geomorphology 2005, 67, 273-281. [CrossRef]

136. Fidanza, M.R.; Caneva, G. Natural biocides for the conservation of stone cultural heritage: A review. J. Cult. Herit. 2019, 38, 271-286. [CrossRef]

137. Rodriguez-Navarro, C.; Rodriguez-Gallego, M.; Chekroun, K.B.; Gonzalez-Munoz, M.T. Conservation of ornamental stone by Myxococcus xanthus-induced carbonate biomineralization. Appl. Environ. Microbiol. 2003, 69, 2182-2193. [CrossRef]

138. Jroundi, F.; Fernández-Vivas, A.; Rodriguez-Navarro, C.; Bedmar, E.J.; González-Muñoz, M.T. Bioconservation of deteriorated monumental calcarenite stone and identification of bacteria with carbonatogenic activity. Microb. Ecol. 2010, 60, 39-54. [CrossRef]

139. Sternberg, T.; Viles, H.; Cathersides, A. Evaluating the role of ivy (Hedera helix) in moderating wall surface microclimates and contributing to the bioprotection of historic buildings. Build. Environ. 2011, 46, $293-297$. [CrossRef]

140. de la Rosa, J.P.M.I.; Warke, P.A.; Smith, B.J. Lichen-induced biomodification of calcareous surfaces: Bioprotection versus biodeterioration. Prog. Phys. Geogr. 2013, 37, 325-351. [CrossRef]

141. Ariño, X.; Ortega-Calvo, J.J.; Gomez-Bolea, A.; Saiz-Jimenez, C. Lichen colonization of the Roman pavement at Baelo Claudia (Cadiz, Spain): Biodeterioration vs. bioprotection. Sci. Total Environ. 1995, 167, 353-363. [CrossRef]

142. de los Ríos, A.; Ascaso, C. Contributions of in situ microscopy to the current understanding of stone biodeterioration. Int. Microbiol. 2005, 8, 181-188. [PubMed]

143. Ranalli, G.; Lustrato, G.; Alfano, G.; Andreotti, A. Long term microbial monitoring of bio-cleaned wall paintings at Pisa. Ann. Microbiol. 2009, 59, 19-29. Available online: www.annmicro.unimi.it (accessed on 8 January 2020).

(C) 2020 by the authors. Licensee MDPI, Basel, Switzerland. This article is an open access article distributed under the terms and conditions of the Creative Commons Attribution (CC BY) license (http://creativecommons.org/licenses/by/4.0/). 